\title{
Nanocarrier-Based Therapeutics and Theranostics Drug Delivery Systems for Next Generation of Liver Cancer Nanodrug Modalities
}

This article was published in the following Dove Press journal: International Journal of Nanomedicine

\author{
Umme Ruman (1) ${ }^{1}$ \\ Sharida Fakurazi ${ }^{2,3}$ \\ Mas Jaffri Masarudin (D) 1,2,4 \\ Mohd Zobir Hussein' \\ 'Materials Synthesis and Characterization \\ Laboratory, Institute of Advanced \\ Technology (ITMA), Universiti Putra \\ Malaysia, Serdang, Selangor 43400, \\ Malaysia; ${ }^{2}$ Laboratory of Vaccine and \\ Immunotherapeutics, Institute of \\ Bioscience Universiti, Putra 43400, \\ Malaysia; ${ }^{3}$ Department of Human \\ Anatomy, Faculty of Medicine \& Health \\ Sciences, Universiti Putra Malaysia, \\ Serdang, Selangor 43400, Malaysia; \\ ${ }^{4}$ Faculty of Biotechnology and \\ Biomolecular Science, Universiti Putra \\ Malaysia, Serdang, Selangor 43400, \\ Malaysia
}

\begin{abstract}
The development of therapeutics and theranostic nanodrug delivery systems have posed a challenging task for the current researchers due to the requirement of having various nanocarriers and active agents for better therapy, imaging, and controlled release of drugs efficiently in one platform. The conventional liver cancer chemotherapy has many negative effects such as multiple drug resistance (MDR), high clearance rate, severe side effects, unwanted drug distribution to the specific site of liver cancer and low concentration of drug that finally reaches liver cancer cells. Therefore, it is necessary to develop novel strategies and novel nanocarriers that will carry the drug molecules specific to the affected cancerous hepatocytes in an adequate amount and duration within the therapeutic window. Therapeutics and theranostic systems have advantages over conventional chemotherapy due to the high efficacy of drug loading or drug encapsulation efficiency, high cellular uptake, high drug release, and minimum side effects. These nanocarriers possess high drug accumulation in the tumor area while minimizing toxic effects on healthy tissues. This review focuses on the current research on nanocarrier-based therapeutics and theranostic drug delivery systems excluding the negative consequences of nanotechnology in the field of drug delivery systems. However, clinical developments of theranostics nanocarriers for liver cancer are considered outside of the scope of this article. This review discusses only the recent developments of nanocarrier-based drug delivery systems for liver cancer therapy and diagnosis. The negative consequences of individual nanocarrier in the drug delivery system will also not be covered in this review.
\end{abstract}

Keywords: nanocarrier, therapeutics, theranostics, drug delivery systems, liver cancer, nanodrug, modalities

\section{Introduction}

Recent statistical reports show that human liver cancer took place as the fifth most common type of cancer. The percentage of liver cancer patients is the highest in Asia and Africa and conversely the lowest prevalence in Europe. ${ }^{1}$ The most common type of liver cancer is hepatocellular carcinoma (HCC). ${ }^{2}$ Approximately $75 \%$ to $90 \%$ of liver cancer exists as hepatocellular carcinoma (HCC) or malignant hepatomas, and it is the most frequent liver cancer. ${ }^{1}$ Liver transplantation and surgery are conventional treatment options in treating HCC patients at early stages, but at the advanced stage of the tumor, surgery is no longer feasible for most cases.

HCC or liver cancer can be treated clinically by chemotherapy besides surgery or transplant. Chemotherapy is the treatment of choice for most cases of liver 
cancer but due to drug toxicity, poor absorption in the tumor cell, multiple drug resistance limits the access of drug to liver cancer cells in chemotherapy. ${ }^{3}$ Most of the liver chemotherapeutics drugs are tyrosine kinase inhibitors which are anti-angiogenesis. This chemotherapeutic drug blocks the signaling pathways that lead to some extend to disrupt the normal cell functions. Eventhough, they primarily inhibit the liver cancer cell proliferation, but they also inhibit the normal cell growth such as hair follicles, bone marrow and gastrointestinal tract cells in the body. ${ }^{4}$ To overcome the limitations of drug toxicity of chemotherapeutics agents, developments of nanotechnology has transpired with therapeutics and theranostics nanocarrier based drug delivery system (DDS).

Nanocarriers (NCs) are nanomaterials of 10-200 nanometers in diameter. They consider as potential vehicles for DDS. $^{5}$ NCs have potentially lowered the cytotoxicity and increase therapeutic efficiency for anti-tumor drugs. ${ }^{6}$ They can also be made to target specific surface receptors of cancer cells. ${ }^{7}$ Most of the chemotherapeutic anticancer drugs have low molecular weight, high toxicity and low specificity and less severe side effects on the patients. As a result, they are often cleared from the circulation before reaching the target site and thus do not accumulate in tumors region. In order to reduce the side effects of chemotherapeutic drugs on normal healthy tissues, nanodrug delivery therapies are required in order to achieve higher efficacy with negligible side effects. However, the designed NCs must have the properties of biodegradability and they must effectively entrap the drug molecules and circulate into the blood stream and target into the desired site with accurate dose. ${ }^{8}$ Nanocarrier-based drug delivery system (NDDS) is able to be tailor-made, by selectively delivering drugs to the cancerous regions and reducing the chances of unspecific delivery to the healthy tissues, thus reducing the side effects of the drugs. Therefore, nano drug delivery is the answer to recapitulate the new option for liver cancer cure.

\section{Nanocarriers in Therapeutic Drug Delivery of Liver Cancer}

NCs have emerged as one of the most powerful and promising tools for drug delivery, imaging and diagnosis due to their characteristics of being able to image the disease tissues, diagnose the condition or detecting the cancer cells at the earlier stage, and simulataneoutsly able to treat the disease. The system is proficiently known as theranostics nanocarriers which presentably able to diagnose and treat the disease at the same time. The system must be biodegradable, having a small size with high surface area and surface modifying properties. They are rapidly evolving as an interesting and effective drug delivery system in liver cancer therapy.

Lately, many researchers have developed various NCs for liver tumor-targeted drug delivery and imaging. Figure 1 shows various nanocarriers used in liver cancer drug delivery system. For example, it was found that polymeric micelles-doxorubicin $\mathrm{NC}$ is effective for growth inhibition of HepG2 cell lines and a better survival rate in a HepG2 xenograft model. ${ }^{9}$

In addition, the theranostic strategy to treat liver cancer is becoming more prominent and in demand. Table 1 shows the list of NCs used for liver cancer therapeutics and diagnostic agents. Moreover, various NCs have been used in the treatment of liver cancer tumors including liposomes, micelles, dendrimers, metal oxide nanoparticles, nanocrystals, carbon nanotubes, magnetic nanoparticles, and nanogels which have been mentioned in Table 1.

\section{Organic Nanocarriers for Therapeutics Applications in Liver Cancer}

A wide range of nanostructures based on organic materials has been advanced for drug delivery systems. The first FDA approved nanodrug was based on nanocarrier liposome which is an organic nanocarrier utilizing doxorubicin as an anticancer agent. ${ }^{10}$ Polymeric nanocarriers are one of the most promising organic NCs for liver cancer. ${ }^{11}$ They are biodegradable, biocompatible, non-toxicity and do not harm autogenous tissue even though it stays prolonged in circulation. The system also has a wide spectrum of therapeutic drugs of liver cancer that can easily be adsorbed, encapsulated or conjugated by the surface of the polymeric nanocarriers. ${ }^{12}$ Tang et al, (2018) studied the biodegradable d-tocopherol polyethylene glycol 1000 succinatepolycaprolactone (TPGS-b-PCL) nanoparticles loaded with sorafenib (SFB) to evaluate the effectiveness of anti-tumor effect in HepG2 hepatoma cells and in HCC xenograft mouse model. ${ }^{13}$ They have successfully found that compared with free SFB, the SFB-loaded TPGS-b-PCL NPs are more effective in suppressing HepG2 cell growth and delayed tumor growth in the HCC xenograft model. Lee et al, (2016) had successfully developed a galactosylated-polylithocholic-acid based doxorubicin loaded nanocarrier for liver cancer therapy which suppresses the growth of hepatic tumor and metastasis in an orthotopic xenograft mouse model of liver 




Figure I Various nanocarriers for liver cancer targeted drug delivery applications.

cancer. ${ }^{14}$ Several nanocarriers like chitosan nanoparticles, liposomes, micelle, dendrimer, lipid nanocarrier can be classified into organic nanocarrier.

\section{Chitosan Nanoparticles}

Chitosan (CS) is a biodegradable polymer of cationic polysaccharide generated by partial deacetylation of chitin. Many researchers have conducted studies on chitosan nanoparticles for liver cancer drug delivery for therapeutic purposes. Ye et al, (2018) evaluated the effect of chitosan coated doxorubicin loaded nanocarrier in liver cancer where it showed excellent inhibitions of cell growth of liver cancer. ${ }^{15}$ Loutfy et al, (2016) synthesized chitosan nanoparticle (CS-NPs) for evaluation of the in vitro human liver cancer cell model (HepG2). They investigated that the cytotoxic effect of CS-NPs towards liver cancer cells is relatively good and they suggested that CS-NPs are suitable for drug delivery proposes for liver cancer. ${ }^{16}$

\section{Micelles}

Polymeric micelles (PM) have been used for liver cancer drug delivery platform due to its core-shell structure, small size and narrow size distribution. ${ }^{17}$ It can solubilize drugs and imaging agents which results in the advantages of diagnosis and therapy for liver cance. ${ }^{18} \mathrm{PM}$ has proven to be highly effective in drug delivery vehicles for liver cancer. Huang et al, (2010) synthesized glycyrrhetinic acid (GA)modified PM loaded with doxorubicin which has great potential in liver targeting therapy. ${ }^{17}$ Hanafy et al (2018) synthesized a novel PM (polyacrylic $\backslash$ poly-galacturonic acid hybrid) loaded with drug galunisertib (LY2157299) which acts as an inhibitor of TGF $\beta$ to treat hepatocellular carcinoma. ${ }^{19}$ Yang et al, (2019) synthesized a nanocarrier of polyethylene glycol-derivatized glycyrrhizic acid (GA)based PM loaded with doxorubicin which is delivered in HepG2 cell line. ${ }^{9}$ This PM demonstrated excellent therapeutic efficacy in vivo compared with free doxorubicin. It potentially inhibited the tumor growth and showed positive survival in a HepG2 xenograft model.

\section{Liposome}

In recent years, several studies have focused on liposomes for controlled drug delivery. Liposomes are relatively stable, consist of biodegradable materials. The drugs are 
Table I List of Nanocarriers, Therapeutic and Diagnostic Agents for Liver Cancer

\begin{tabular}{|c|c|c|c|c|c|}
\hline Nanocarriers & Drugs & $\begin{array}{l}\text { Diagnostic } \\
\text { Agent }\end{array}$ & Cell Lines & Outcomes & Reference \\
\hline Micelles & Sorafenib & Polymeric micelles & $\begin{array}{l}\text { HepG2-Luc tumor- } \\
\text { bearing mice }\end{array}$ & $\begin{array}{l}\text { Micelles show higher tumor } \\
\text { growth inhibition in vivo } \\
\text { systems. }\end{array}$ & {$[110]$} \\
\hline $\begin{array}{l}\text { Gadolinium co-loaded } \\
\text { liposomes }\end{array}$ & Sorafenib & Gadolinium & $\begin{array}{l}\text { HepG2 and mouse } \\
\text { hepatocarcinomatous } \\
\text { cells }(\mathrm{H} 22)\end{array}$ & $\begin{array}{l}\text { The imaging time is long and } \\
\text { signal enhancement is high, } \\
\text { good inhibition of cells growth }\end{array}$ & {$[\mathrm{III}]$} \\
\hline $\begin{array}{l}\text { Lipid-polymer hybrid } \\
\text { nanoparticles }\end{array}$ & $\begin{array}{l}\text { Sorafenib and } \\
\text { doxorubicin }\end{array}$ & - & $\begin{array}{l}\text { HepG2 HCC cells in } \\
\text { xenograft mouse } \\
\text { models }\end{array}$ & $\begin{array}{l}\text { Significantly enhanced } \\
\text { antitumor efficiency in HCC }\end{array}$ & {$[112]$} \\
\hline Polymer nano-core shell & $\begin{array}{l}\text { Hydrophobic drug } \\
\text { (sorafenib), and } \\
\text { hydrophilic drug } \\
\text { (doxorubicin) }\end{array}$ & - & HepG2 & Inhibits cell proliferation & [II3] \\
\hline $\begin{array}{l}\text { Nanostructured lipid } \\
\text { carriers (NLC) }\end{array}$ & Sorafenib & - & HepG2, Нер3B, Huh7 & $\begin{array}{l}\text { Enhanced anti-tumor activity of } \\
\mathrm{HCC}\end{array}$ & {$[32]$} \\
\hline $\begin{array}{l}\text { Silica coated Gold } \\
\text { Nanoparticle }\end{array}$ & Doxorubicin & Gold Nanoparticle & $\begin{array}{l}\text { SMMC- } 772 \text { I tumor- } \\
\text { bearing mice }\end{array}$ & $\begin{array}{l}\text { Inhibit the tumor growth } \\
\text { in vivo significantly and reduce } \\
\text { the toxicity systematically }\end{array}$ & {$[114]$} \\
\hline $\begin{array}{l}\text { Polymer containing } \\
\text { hydroxyapatite (HAP) shell } \\
\text { and a magnetic core of iron } \\
\text { oxide nanoparticles }\end{array}$ & $\begin{array}{l}\text { Doxorubicin and/ } \\
\text { or curcumin }\end{array}$ & Iron xide & HEpG2 & $\begin{array}{l}\text { Effectively inhibit the growth } \\
\text { HEpG2 (liver) cancer cells, }\end{array}$ & {$[115]$} \\
\hline Zinc oxide quantum dots & & - & HepG2 & $\begin{array}{l}\text { Induce the cytotoxicity and } \\
\text { apoptosis in HepG2 cancer } \\
\text { cells }\end{array}$ & [116] \\
\hline $\begin{array}{l}\text { Chitosan }(\mathrm{CHI}) \text { modified } \\
\text { single walled carbon } \\
\text { nanotubes (SWNTs) }\end{array}$ & Doxorubicin & - & $\begin{array}{l}\text { HCC SMMC-772I } \\
\text { cell lines }\end{array}$ & $\begin{array}{l}\text { kill the HCC SMMC- } 772 \text { I cell } \\
\text { lines and depressed the growth } \\
\text { of liver cancer compare to free } \\
\text { doxorubicin. }\end{array}$ & [49] \\
\hline $\begin{array}{l}\text { Chitosan coated multiwall } \\
\text { carbon nanotubes }\end{array}$ & Doxorubicin & - & $\begin{array}{l}\text { HepG2, mice bearing } \\
\text { the } \mathrm{H} 22 \text { tumor }\end{array}$ & $\begin{array}{l}\text { higher antitumor activity and } \\
\text { stronger fluorescent intensity } \\
\text { have been shown in tumor } \\
\text { tissue }\end{array}$ & [48] \\
\hline $\begin{array}{l}\text { Nanocomposite based on } \\
\text { graphene oxide }\end{array}$ & Doxorubicin & Gadolinium & $\begin{array}{l}\text { Human hepatoma } \\
\text { cells }\end{array}$ & $\begin{array}{l}\text { Exhibited cytotoxic effect upon } \\
\text { liver cancer cells }\end{array}$ & {$[117]$} \\
\hline $\begin{array}{l}\text { Porous magnetic } \\
\text { nanoclusters with iodinated } \\
\text { Oil }\end{array}$ & Doxorubicin & $\begin{array}{l}\text { Magnetic } \\
\text { Nanoclusters }\end{array}$ & $\begin{array}{l}\text { Liver tumors in rabbit } \\
\text { model }\end{array}$ & $\begin{array}{l}\text { Enhance the liver cancer cell } \\
\text { death significantly }\end{array}$ & [118] \\
\hline Silica nanoparticles & $\begin{array}{l}\text { Cetuximab and } \\
\text { Doxorubicin }\end{array}$ & - & $\begin{array}{l}\text { HepG2 cells in vitro } \\
\text { and in vivo }\end{array}$ & $\begin{array}{l}\text { Better anticancer efficiency } \\
\text { than free cetuximab and free } \\
\text { doxorubicin }\end{array}$ & {$[119]$} \\
\hline
\end{tabular}

(Continued) 
Table I (Continued).

\begin{tabular}{|c|c|c|c|c|c|}
\hline Nanocarriers & Drugs & $\begin{array}{l}\text { Diagnostic } \\
\text { Agent }\end{array}$ & Cell Lines & Outcomes & Reference \\
\hline Dextran & - & $\begin{array}{l}\text { Super paramagnetic } \\
\text { iron oxide } \\
\text { nanoparticles } \\
\text { (SPIONs) }\end{array}$ & $\begin{array}{l}\text { Human hepatocellular } \\
\text { cells, HepG2 }\end{array}$ & $\begin{array}{l}\text { Effective antitumor effect and } \\
\text { magnetic resonance }\end{array}$ & {$[120]$} \\
\hline $\begin{array}{l}\mathrm{Fe}_{3} \mathrm{O}_{4} / \mathrm{MnO} \text { hybrid } \\
\text { nanocrystals }\end{array}$ & - & $\mathrm{Mn}^{2+}$ & $\begin{array}{l}\text { Human hepatocellular } \\
\text { carcinoma }(\mathrm{HCC}) \text { in } \\
\text { orthotopic xenograft } \\
\text { model }\end{array}$ & $\begin{array}{l}\text { Shows greater imaging effect } \\
\text { by detecting the HCC with } \\
\text { a high degree }\end{array}$ & {$[121]$} \\
\hline $\begin{array}{l}\text { Gadolinium-embedded iron } \\
\text { oxide (GdIO) }\end{array}$ & - & Gd & Liver of BALB/c mice & Efficient tumor imaging & [122] \\
\hline Nanofiber & Doxorubicin & - & $\begin{array}{l}\mathrm{H} 22 \text {, an aggressive } \\
\text { murine liver cancer } \\
\text { cell line SMMC772I } \\
\text { cell line }\end{array}$ & $\begin{array}{l}\text { Provide good tumor-targeting } \\
\text { activity. }\end{array}$ & [123] \\
\hline $\begin{array}{l}\text { Alginate/doxorubicin- } \\
\text { modified alginate complex } \\
\text { nanoparticles), }\end{array}$ & Doxorubicin & - & HepG2 Cells & $\begin{array}{l}\text { The inhibition rate of tumor } \\
\text { growth is high }\end{array}$ & [124] \\
\hline $\begin{array}{l}\text { Superparamagnetic iron } \\
\text { oxide nanoshells }\end{array}$ & Doxorubicin & $\begin{array}{l}\text { Superparamagnetic } \\
\text { iron oxide }\end{array}$ & $\begin{array}{l}\text { In vivo liver tumor } \\
\text { model }\end{array}$ & $\begin{array}{l}\text { Effective antitumor effect and } \\
\text { imaging }\end{array}$ & [52] \\
\hline $\begin{array}{l}\text { Polyethylene glycol } \\
\text { modified phospholipid } \\
\text { micelles }\end{array}$ & Sorafenib & - & HepG2 Cells & Antitumor effectiveness is high & [3] \\
\hline Dendrimer & Doxorubicin & & HepG2 Cells & $\begin{array}{l}\text { Inhibits the growth of liver } \\
\text { cancer cells with a better } \\
\text { efficiency. }\end{array}$ & [30] \\
\hline Nanofiber & Cisplatin & - & & Prevent tumor recurrence & [54] \\
\hline $\begin{array}{l}\text { Lipoprotein modified silica } \\
\text { nanoparticles }\end{array}$ & $\begin{array}{l}\text { Docetaxel and } \\
\text { Thalidomide }\end{array}$ & - & $\begin{array}{l}\text { HepG2 human } \\
\text { hepatocellular liver } \\
\text { carcinoma cell line }\end{array}$ & $\begin{array}{l}\text { Achieve effective } \\
\text { chemotherapy of liver cancer }\end{array}$ & [37] \\
\hline Nanofiber & Doxorubicin & - & $\begin{array}{l}\text { Mammary carcinoma } \\
\text { EMT6 cells }\end{array}$ & $\begin{array}{l}\text { Effective inhibition of cancer } \\
\text { cells and in vivo release and } \\
\text { biodistribution show greater } \\
\text { outcome }\end{array}$ & [36] \\
\hline Polymeric micelles & Doxorubicin & - & HCC cell line, HepG2 & $\begin{array}{l}\text { Good tumor growth inhibition } \\
\text { and overall survival rate in } \\
\text { a HepG } 2 \text { xenograft model. }\end{array}$ & [9] \\
\hline $\begin{array}{l}\text { Folate-conjugated } \\
\text { PEGylated PLGA } \\
\text { nanoparticles }\end{array}$ & Sorafenib & SPION & BEL7402 cancer cells & $\begin{array}{l}\text { Suppress the tumor cell } \\
\text { proliferation effectively and } \\
\text { improve the anticancer efficacy }\end{array}$ & {$[125]$} \\
\hline
\end{tabular}


entrapped by the inner core of the liposome. ${ }^{20}$ It has been effectively used as a carrier system for delivering a variety of therapeutic agents due to its biocompatibility, low toxicity, biodegradability and capability of incorporating both hydrophilic and hydrophobic drugs. ${ }^{21,22}$ Wang et al, (2018) studied liposome decorated with antibodies of CD147, a polyclonal antibody highly precence in liver cancer cell lines and HCC tissues. In their study, CD147 was used as the target molecule to construct a new targeted liposome-based carrier loaded with doxorubicin. The result showed that this nanocarrier exhibit a higher cytotoxic effect on Huh-7 and HepG2 cells as well as the HCC 3736 model. ${ }^{23}$ Persico et al, (2018) investigated liposomes coated with chitosan and uncoated liposomes loaded with butyric acid (BA) to evaluate the anticancer effect of hepatoblastoma (HB) in HepG2 cell line. ${ }^{24}$ They concluded that BA-loaded liposomes coated with chitosan showed higher cytotoxicity effect than both uncoated liposomes and free BA. ${ }^{24} \mathrm{He}$ et al, (2018) investigated in vitro and in vivo drug release studies on Sorafenib-loaded liposomes compared with free Sorafenib using Hep3B tumorbearing xenograft nude mice. The experimental evidence suggested that biocompatibility, biotoxicity and anti-tumor effect were improved using sorafenib-loaded liposome compared with free sorafenib. ${ }^{25}$ According to the results, liposome represents a novel and suitable nanocarrier-based treatment strategy for advanced HCC therapy in the future.

\section{Dendrimer}

Dendrimer-based drug delivery systems for antitumor therapy have a great advantage. The physico-chemical properties, such as structure and size, aqueous solubility, mono-dispersity and the high drug delivery ability make dendrimer a unique nanocarrier for drug delivery application. ${ }^{26}$ Moreover, dendrimer has efficient renal filtration properties. ${ }^{27}$ Wojnarowicz et al, (2018) synthesized a dendrimer based multifunctional NCs coated with polydopamine (PDA) and magnetite nanoparticles $\left(\mathrm{Fe}_{3} \mathrm{O}_{4}\right)$. The synthesized nanocarriers were reported as nontoxic and it can load the drug photothermal and chemotherapeutic agents effectively to treat liver cancer cells at the solution of low nanoparticles. ${ }^{28}$ Sharma et al, (2017) reported that the surface of dendrimers has water soluble functional groups that are responsible for the excellent water solubility. ${ }^{29}$ Liver cancer drugs are hydrophobic, the inner core and branches of dendrimers have the characteristic of encapsulating hydrophobic drugs. Fu et al, (2014) had have developed a multifunctional dendrimer-based nanocarrier conjugated with polyethylene glycol, modified with lactobionic acid and encapsulated with doxorubicin for liver cancer therapy. They found that the nanocarrier effectively inhibits the growth of liver cancer cells. ${ }^{30}$ Jain et al (2014) have carried out the synthesis of a nanoconjugate of glycyrrhizin-dendrimer modified with carbon nanotube. ${ }^{31}$ The liver cancer drug, doxorubicin was loaded and entrapped by the dendrimer and carbon nanotubes. The cytotoxicity, loading and release studies indicate that this dendrimer-based nanocarrier seems to be an effective vehicle for encapsulation of ionizable drugs of liver cancer. $^{31}$

\section{Lipid Nanocarriers}

The lipid-based NCs provide an option in the development of a specific nanotherapeutics delivery system for different liver cancer drugs. A nanostructured lipid carrier was synthesized by Bondì et al, (2015) for the controlled release of sorafenib drug to see the anticancer activity compared to free drug. They suggest that lipid based nanocarrier can be a good delivery agent for liver cancer for therapeutic application. ${ }^{32}$ Furthermore, Zhao et al, (2015) developed a lipid nanocarrier that delivers the doxorubicin and curcumin drug in mice model and they found that lipid nanocarrier has the excellent inhibitory effect on tumor growth with its high encapsulation efficacy, uniform particle size and sustained release profile. ${ }^{33}$

\section{Organic Nanofiber}

Organic nanofibers have been used as vectors for drug delivery for liver cancer. The chemotherapeutic drug-bearing nanofiber simultaneously inhibits metastasis and tumor growth of liver cancer cells. Ebara et al, (2015) constructed an organic nanofiber containing anticancer drug, paclitaxel and therapeutic gene, miRNA-145 to see the effect of both drug and gene delivery to liver cancer. It has shown that the reduction of growth of a liver tumor and prevents metastasis. ${ }^{34} \mathrm{Ji}$ et al, (2018) synthesized doxorubicin-conjugated nanofibers which have the property of sustained release drug for inhibiting tumor growth in an SMMC7721 cell line in the mouse model. ${ }^{35}$ Liu et al (2013) investigated a doxorubicin-loaded nanofiber as a chemotherapeutic system against hepatic carcinoma. They observed significant anti-tumor efficacy in the resulting nanofiber. ${ }^{36}$

\section{Inorganic Nanocarriers}

Inorganic nanocarriers are generally had physical properties, such as optical absorption, fluorescence (semiconductor QDs), and magnetic moment (e.g., iron oxides), useful 
reactive groups for different biomolecules in order to achieve a biological functionality, such as active targeting of tissues or cells. Table 1 summarised various inorganic nanocarriers for the application of liver cancer nano drug delivery. For example, Ao et al, 2018 studied lipoprotein modified silica nanoparticles loaded with Docetaxel and Thalidomide to observe the cytotoxicity of HepG2 human hepatocellular liver carcinoma cell line and found effective tumor killing on liver cancer. ${ }^{37}$

\section{Graphene Oxide-Based Nanocarriers}

Graphene oxide nanocarriers have excellent drug loading capacity. The property of high electron transfer of individual graphene sheets makes them a good carrier for drug delivery application. ${ }^{38}$ Due to their high surface area, graphene-based nanocarriers can form specific interactions with various drug molecules. ${ }^{39}$ Yang et al (2016) had indicated a targeted drug delivery system of graphene oxide with carboxymethyl chitosan, fluoroscein isothiocyanate, lactobionic acid and anticancer drug doxorubicin. The nanocarrier has induced cell death after $24 \mathrm{hrs}$ of incubation and shown higher biocompatibility with liver cancer cell lines. ${ }^{40}$ Yuan et al, 2015 indicated that a combination of folic acid, monoclonal antibodies and gold nanoparticles-based graphene nanocomposites promoted HepG2 cell apoptosis with drug targeting and controlled release properties. ${ }^{41}$

\section{Polylactic-Co-Glycolic Acid (PLGA) Nanoparticles}

Poly(lactic-co-glycolic) acid PLGA nanoparticles are a copolymer of two monomers; lactic and glycolic acids. PLGA can be obtained as a synthetic polymer. Due to its biocompatibility, the US Food and Drug Administration and the European Medicine Agency has been approved PLGA for drug delivery. ${ }^{42}$ Recent studies have shown that PLGA nanoparticles have high drug loading capacity, good specificity, biocompatibility and efficacy in drug delivery of liver cancer. Gao et al, (2015) formulated polylactic-co-glycolic acid (PLGA) nanoparticles, coated with lipid and modified with a CXCR4 antagonist to deliver anticancer drugs sorafenib into HCC liver cancer. It was found that the sorafenib-loaded PLGA nanocarrier enhanced the anti-angiogenic effect, delayed the tumor progression and increased survival of the orthotopic HCC model mouse. ${ }^{43} \mathrm{Li}$ et al, 2015 formulated a poly(lactide-co -glycolide) conjugated with tocopheryl polyethylene glycol 1000 succinate (PLGA TPGS) nanoparticles loaded with oleanolic acid (OA) to improve the anticancer efficacy of liver cancer treatments. They successfully found that PLGA nanoparticles loaded with OA shows the excellent anticancer effect on human liver cancer cell line HepG2 cells and in vivo model. In the work of Dangi et al, (2014), PLGA nanoparticles conjugated with lactobionic acid and loaded with 5-Fluorouracil (5-FU) showed a good anticancer efficacy on the human cancer cell line, HepG2 compared with free 5-FU. ${ }^{44}$

\section{Carbon Nanotubes}

Carbon nanotubes (CNTs) are needle-like shape materials that able to carry therapeutic drugs to the cellular component. ${ }^{45}$ According to the study of He et al (2017), CNTs are potentially considered excellent nano-vehicles for the delivery of different therapeutic agents due to their small size and mass, high electrical, strong mechanical potency and thermal conductivity. ${ }^{46}$ CNTs exhibit biocompatibility, low toxicity, fewer side effects, high treatment efficacy with low drug doses in tumor-targeted drug delivery. ${ }^{47}$ Qi et al (2015) had used CNTs as a carrier to deliver the doxorubicin drug in vivo liver tumor model and found excellent antitumor activity in the Hep2 cell lines. ${ }^{48}$ Ji et al (2012) studied doxorubicin-loaded chitosan folic acid conjugate single walled CNTs for controlled release in HCC cell lines. They successfully found that CNTs-based nanocarrier can effectively kill the HCC cells and depress the liver cancer growth than free doxorubicin in nude mice. ${ }^{49}$ Elsayed et al (2019) has designed sorafenib-loaded carbon nanotubes (CNTs) that showed the therapeutic efficacy against HCC. ${ }^{50}$

\section{Superparamagnetic Iron-Oxide Nanoparticles}

Superparamagnetic iron-oxide nanoparticles (SPIONs) have shown significant performance in the field of liver cancer therapy and diagnosis. Azzariti et al (2017) had synthesized polyethylene-glycol modified micelles loaded with SPIONs and sorafenib to test the liver cancer inhibition effect. Due to the impact of the magnetic field, SPIONs have made potential targeting ability to specific sites in liver cancer. They administered SPIONs in the human hepatocellular carcinoma (HepG2) cells in an in vitro system to evaluate tumor cell targeting efficacy of the sorafenib-loaded superparamagnetic micelles and they found that this nanocarrier had controlled drug loading efficacy and better inhibition effect. ${ }^{3}$

\section{Nanoshell}

Nanoshells have attracted tremendous attention over the past few decades as a promising tool for liver cancer therapy. ${ }^{51}$ It is a self-assembled polymer forming a core 
or shell structure and has been used for liver imaging as well. $^{52}$ One of the most useful nanoshells is gold nanoshells. According to Liu et al, (2010), gold nanoshell showed good targeting ability to liver cancer cells, for example, BEL7404 and BEL-7402 without affecting the normal healthy liver cell like HL-7702. ${ }^{53}$

\section{Inorganic Nanofiber}

Both organic and inorganic nanofibers are considered as good carriers for drug delivery of liver cancer. Zhang et al, (2014) investigate cisplatin-loaded, multilayered polylactide electrospun nanofiber in liver cancer in mice. They evaluate the inhibitory effect of cisplatin-loaded nanofiber in the H22 cell lines. The nanofiber improved tumor cytotoxicity and prolonged drug release and prevent tumor recurrence following HCC surgery. ${ }^{54}$

\section{Various Nanocarriers for Theranostic Drug Delivery for Liver Cancer}

The theranostic delivery literally means putting together diagnostic and therapeutic agents on a carrier to cure and diagnose cancer. Theranostic nanocarriers have emerged to diagnose and treat the diseases at the cellular and molecular level. Figure 2 represents the theranostic model of nanocarriers. Currently, the theranostic delivery-based approach has been explored effectively for treating liver cancer. The therapeutic agents in theranostic nanocarriers include chemotherapeutics drugs, proteins, peptides, gene and genetic materials. Diagnostic agents that are commonly used in theranostic nanocarriers include gadolinium, fluorescent dyes, quantum dots, superparamagnetic iron oxides, radionuclides, heavy elements, such as iodine for optical imaging, magnetic resonance imaging (MRI), nuclear imaging and computed tomography. ${ }^{55}$ Table 2 shows the list of nanocarriers used for liver cancer theranostic drug delivery. For example, Zhang et al, (2016) used lipid-micelles as nanocarrier and used gadolinium as a contrast agent for MRI/photoacoustic imaging (PAI) in HepG2 tumor-bearing mice. ${ }^{56}$

\section{Gadolinium as a Diagnostic Agent for Liver Cancer}

FDA approves gadolinium (Gd) as a diagnostic agent for magnetic resonance imaging (MRI) of the liver to detect and characterize the tumors in liver cancer. Liu et al (2011) had designed novel multifunctional polymeric nanoparticles modified with gadolinium-diethylenetriamine pentaacetic acid (Gd-DTPA) to deliver Gd-DTPA to the tumor area and achieve the early diagnosis of hepatocellular carcinoma (HCC). ${ }^{57}$ Luo et al (2011) had carried out the synthesis, characterization and imaging of gadoliniumbased multifunctional peptide dendritic MRI probes for liver imaging. The properties and targeting effect of gadolinium containing dendritic have shown a strong impact on their behavior in vitro and in vivo as MRI contrast agents to detect the tumors. ${ }^{58}$

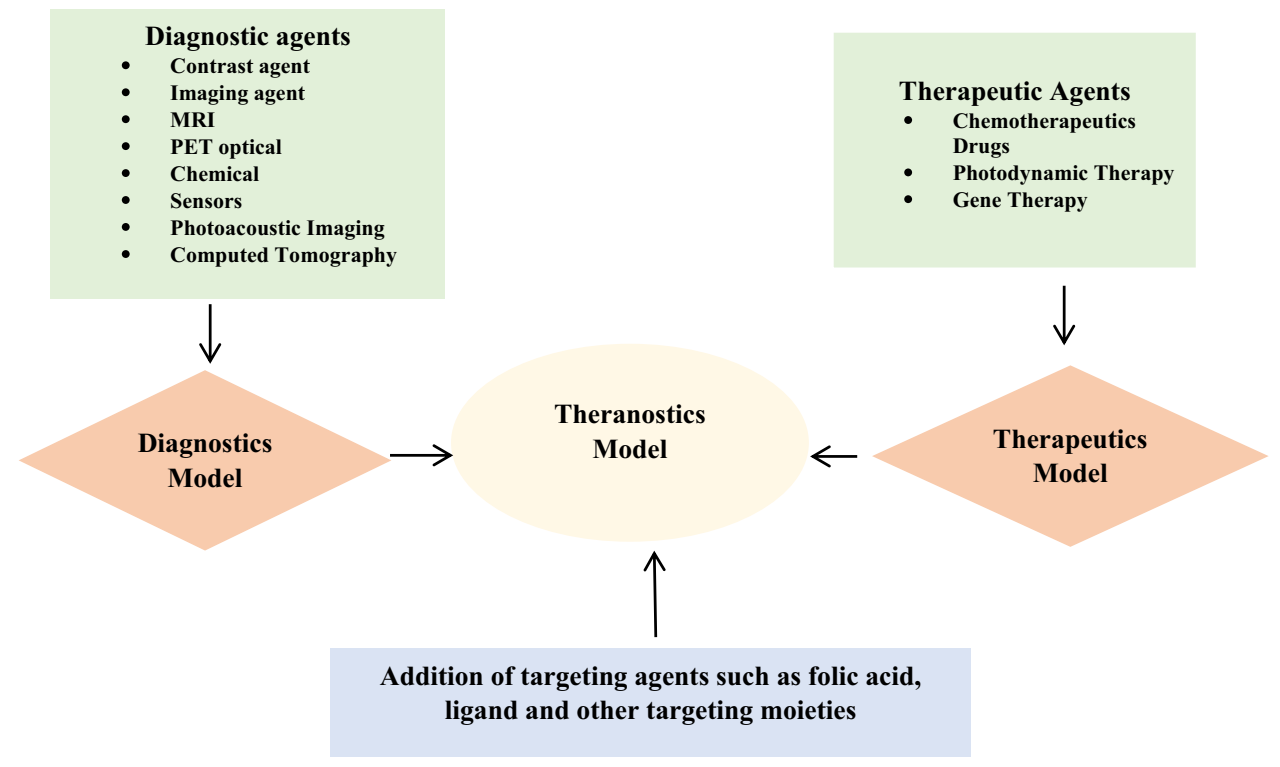

Figure 2 Theranostics nanocarrier model. 
Table 2 Theranostics Nanocarriers Delivery Agents for Liver Cancer

\begin{tabular}{|c|c|c|c|c|c|}
\hline Nanocarriers & Drug & Diagnostic Agent & Technique & Target & References \\
\hline SPION & Doxorubicin & Iron oxide & MRI & $\begin{array}{l}\text { Liver cancer of rabbit } \\
\text { bearing orthotopic } \\
\text { tumor }\end{array}$ & {$[126]$} \\
\hline Micelle & Sorafenib & SPION & MRI & $\begin{array}{l}\text { Cancer of } \\
\text { subcutaneous } \mathrm{H} 22 \text { cells } \\
\text { bearing mice }\end{array}$ & {$[127]$} \\
\hline $\begin{array}{l}\text { Polymeric } \\
\text { nanoparticles }\end{array}$ & Doxorubicin & SPION & MRI & $\begin{array}{l}\text { Rabbits bearing VX2 } \\
\text { rabbit tumor }\end{array}$ & [128] \\
\hline Lipid-micelles & - & Gadolinium & $\begin{array}{l}\text { MRI/photoacoustic imaging } \\
\text { (PAI) }\end{array}$ & $\begin{array}{l}\text { HepG2 tumor-bearing } \\
80 \text { nude mice }(22-24 \mathrm{~g})\end{array}$ & {$[56]$} \\
\hline Micelles & $\begin{array}{l}\text { Mitoxantrone } \\
(M X)\end{array}$ & Micelles & $\begin{array}{l}\text { MRI/upconversion } \\
\text { luminescence (MRI/UCL) }\end{array}$ & $\begin{array}{l}\text { Human hepatocellular } \\
\text { carcinoma cell line BEL- } \\
7404\end{array}$ & [59] \\
\hline Dendrimer & - & Polydopamine & $\begin{array}{l}\text { CT (chemotherapy) and PTT } \\
\text { (photothermal therapy) }\end{array}$ & HepG2 & [129] \\
\hline $\begin{array}{l}\text { Polymeric } \\
\text { nanoparticle }\end{array}$ & - & Gadolinium & MRI & $\mathrm{HCC}$ & [57] \\
\hline $\begin{array}{l}\text { Gadolinium-based } \\
\text { silica-coated } \\
\text { nanocrystals }\end{array}$ & - & Gadolinium & PDT and MRI & BNL I ME A. 7R.I cell & {$[130]$} \\
\hline Dextran & - & Iron oxide nanoparticles & - & HepG2 & {$[120]$} \\
\hline Micelles & Doxorubicin & Super magnetic iron oxide & $\begin{array}{l}\text { Targeted therapeutic and } \\
\text { imaging strategy against liver } \\
\text { cancer. }\end{array}$ & HepG2 & {$[|3|]$} \\
\hline $\begin{array}{l}\text { Calcium phosphate } \\
\text { nanoparticles }\end{array}$ & Doxorubicin & $\begin{array}{l}\text { Diethylenetriaminepentaacetic } \\
\text { acid gadolinium }\end{array}$ & MRI & $\begin{array}{l}\text { BEL-7402 and HepG2 } \\
\text { cell lines }\end{array}$ & [132] \\
\hline
\end{tabular}

Abbreviations: SPION, Superparamagnetic iron oxide nanoparticle; MRI, magnetic resonance imaging; PDT, photodynamic therapy.

\section{Superparamagnetic Iron Oxide Nanoparticles as a Diagnostic Agent for Liver Cancer}

Superparamagnetic iron oxide nanoparticles (SPIONs) are important in the field of theranostic delivery because of their magnetic property. SPIONs have been used as diagnostic agents for magnetic resonance imaging (MRI) to detect liver cancer as they can be targeted to specific sites of liver cancer through the effect of the magnetic field. SPION can be used as a therapeutic agent, as well as an MRI contrast agent in liver cancer cell line. It was found that SPION was degraded into a soluble form of iron or non-toxic ions in the body and cleared from the blood by phagocytosis. They are metabolized in cell lysosomes. ${ }^{59}$ There are a few types of superparamagnetic iron oxide (SPIO) in the market such as
Ferumoxytol, Ferumoxides, Ferucarbotran, Ferumoxtran-10, and Ferropharm. They have been designed and clinically tested as MRI contrast agents. Ferumoxytol comprised of iron oxide nanoparticles surrounded by a carbohydrate coat. It is a potential imaging approach for evaluating certain liver tumors. ${ }^{60}$ Ferumoxide (dextran-coated SPION) and Ferucarbotran (carboxydextran-coated SPION) are the two SPIONS clinically approved for liver cancer imaging. ${ }^{61}$ SPIONs and sorafenib loaded nanoformulation were prepared by Azzariti et al, (2017) based on polyethylene glycolmodified phospholipid micelles. They investigate their drug delivery for hepatocellular carcinoma and found that SPION could enhance imaging by magnetic targeting. ${ }^{3}$ However, iron oxide nanoparticles had limited clinical use in imaging liver, spleen and lymph nodes, due to the passive 
accumulation in these organs. Therefore, FDA has withdrawn the approval of iron oxide nanoparticles and the usage was discontinued as MRI contrast agents in the US Meanwhile, other SPIONs, namely ferumoxsil (Lumirems/ Gastromarks) for oral administration and ferumoxide (Endorems/Feridexs) are available as intravenous injection, were also discontinued for economic and safety issues reasons. ${ }^{62-65}$

\section{Quantum Dots as a Diagnostic Agent for Liver Cancer}

Quantum dots (QDs) are one of the most efficient diagnostic agents used in theranostic applications for diagnosis and therapy of liver cancer due to their unique physico-chemical characteristics, especially photoluminescence characteristics. Olerile et al, (2017) showed that HepG2 cells of liver tumors were detected by the NLC nanostructured lipid carrier-loaded QDs. ${ }^{66}$ Das \& Mohapatra (2017) found QDs are suitable for targeted imaging of liver cancer cells, where QDs are incorporated as a platform of bioimaging systems for liver cancer detection and imaging. ${ }^{67}$ Shao et al (2015) applied QDs-based liposomes carrier for liver cancer imaging of suicide gene therapy. ${ }^{68}$ Al-Jamal et al (2009) demonstrated that the near-infrared fluorescence imaging accumulated efficiently in liver cancer cells of mice via QD fluorescence. In addition to their findings, QDs can be encapsulated within the lipid bilayers of liposomes to form nanoscale vesicles and perform as a contrast agent to identify liver cancer imaging. ${ }^{69}$

\section{Nanocarriers Interaction with Liver, Cellular Uptake, Biodistribution and Clearance}

The liver consists of two types of major cells: parenchymal cells and non-parenchymal cells. Parenchymal cells can be further subcategorized into hepatocytes and cholangiocytes, while non-parenchymal cells include Kupffer cells (KCs), liver sinusoidal endothelial cells (LSECs) and hepatic stellate cells (HSCs). ${ }^{70} \mathrm{KCs}$, LSECs, HSCs and hepatocytes are responsible for various physiological functions of the liver including cellular uptake of the nanocarrier. The huge portion of NCs are taken by KCs, followed by LSECs, HSCs and less by hepatocytes cells. ${ }^{71}$ Figure 3 shows nanocarriers uptake by different liver cells. The liver metabolizes the drugs and NCs. The administered NCs should be eliminated from the body by degradation or excretion. However, some NCs are very stable and difficult to be broken down, while some NCs are biodegradable and easy to be metabolized (Kang \& Song, 2018).$^{72}$ After administration, NCs which are less than $6 \mathrm{~nm}$ in size can be excreted by renal within hours to days. The non-degradable nanocarriers which are larger than $6 \mathrm{~nm}$ in size are taken up by the mononuclear phagocyte system (MPS). Hepatobiliary excretion of nanocarrier $(>6 \mathrm{~nm})$ is a route for NCs removal through the liver. The liver is the



Figure 3 Nanocarriers (NCs) uptake in different liver cells. 


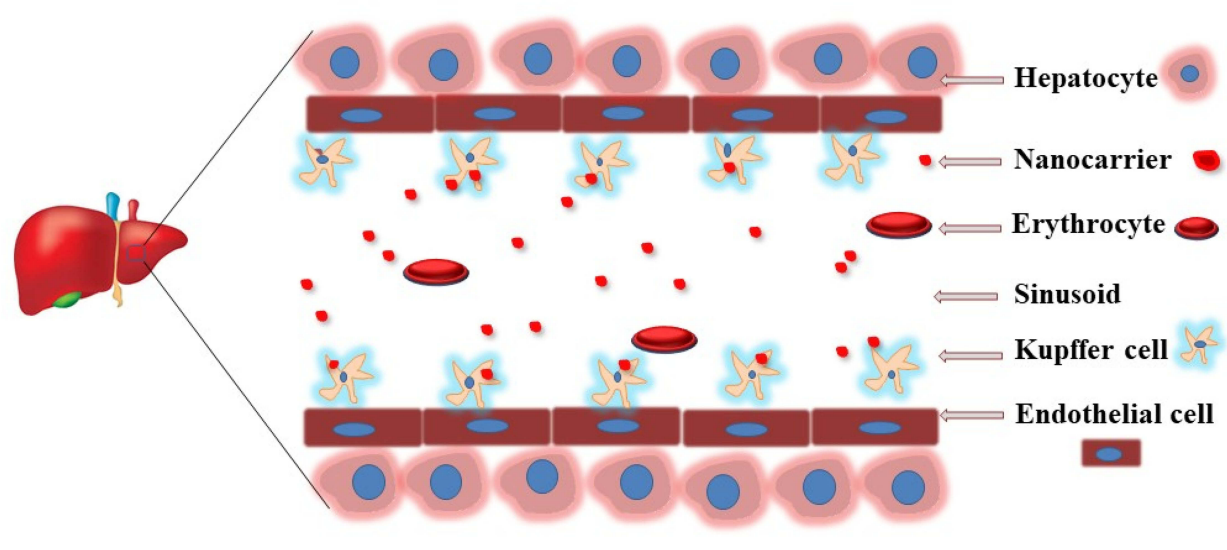

Figure 4 Nanocarriers elimination in liver from the bloodstream.

primary organ of the MPS that entraps majority of the administered NCs. The MPS and renal system compete with the tumor for circulating NCs and eliminate $99 \%$ of the administered NCs. The MPS contains phagocytic cells such as macrophages which consist of the liver, spleen, lymph nodes, bone marrow and skin. Most administered NCs are sequestered by the liver and the spleen. Macrophages in the liver include KCs and liver sinusoids along with endothelial cells (Wilhelm et al, 2016). ${ }^{73}$ Figure 4 shows the elimination of nanocarriers in the liver from the bloodstream. NCs sequester from the body through macrophage. The mechanism of NCs sequestration by macrophages is phagocytosis, macropinocytosis, caveolin-mediated endocytosis, clathrinmediated and endocytic pathways. ${ }^{74}$ NCs can enter liver cells via several endocytic pathways. Passive penetration may occur through the plasma membrane while active penetration occurs mainly via endocytosis. ${ }^{75}$ The process of NCs uptake into cells begins with the nanocarriers being enclosed within the early endocytic vesicles and thus not directly carried into the cytosol. Endocytosis can occur through pinocytosis or phagocytosis pathways. ${ }^{76}$ In pinocytosis, NCs are internalized by small vesicles while in phagocytosis the cells such as monocytes/macrophages, neutrophils and dendritic cells engulf the NCs and form intracellular phagosomes. ${ }^{75}$ Pinocytosis further subdivided into four different categories; macropinocytosis, clathrin-mediated endocytosis, caveolinmediated endocytosis and clathrin- and caveolinindependent endocytosis. ${ }^{77}$ It was reported that graphene oxide (GO) NCs could be internalized by HepG2 cells but reduced $\mathrm{GO}(\mathrm{rGO})$ or adsorbed onto the cell surface without internalization. ${ }^{78}$ Phagocytosis occurs mainly in liver KCs. ${ }^{79}$ For instance, polyalkyl cyanoacrylate nanoparticles loaded with an anticancer agent, doxorubicin into 200-300 $\mathrm{nm}$ size substantially accumulated in hepatic $\mathrm{KCs}$, which then acted as a reservoir, slowly releasing doxorubicin as the particles degraded. ${ }^{80}$ Li et al, 2014, synthesized cholesteryl pullulan nanoparticles (CHP) which enhanced the efficiency of drug delivery in human hepatocellular carcinoma by clathrinmediated endocytosis and micropinocytosis pathways. These pathways were involved in the uptake of CHP nanoparticles. ${ }^{81}$ However, HepG2 cells have no endogenous caveolin, so they are unable to mediate the nanocarriers uptake by caveolae mediated endocytosis. ${ }^{82}$ Figure 5 shows the clearance of nanocarriers from the liver. According to the study by Zhang et al, (2016), NCs enter the liver via the portal vein and traverse into the hepatic sinusoid and sequestered in KCs. Based on their physico-chemical properties, NCs are filtered into the space of diseases and endocytosed by hepatocytes, followed by the NCs enter the bile duct and travel through the hepatic ducts. After that according to the state of the digestive system and bile production, NCs may first collect inside the gallbladder and enter inside the common bile duct. From there, NCs are excreted into the duodenum and eventually traverse into the gastrointestinal tract and eliminate from the body. ${ }^{83}$

\section{Targeting Approaches for Nanocarrier Based Drug Delivery in Liver Cancer}

Nanocarrier drug delivery targeted to a tumor cell is based on active and passive targeting interactions. In active targeting, ligands are attached on the surface of each nanocarrier which is complementary to the tumor target sites. In passive targeting, the nanocarrier surface is coated with stabilizing agents which help to cross the tumor vascular barrier through intercellular gaps. This is 


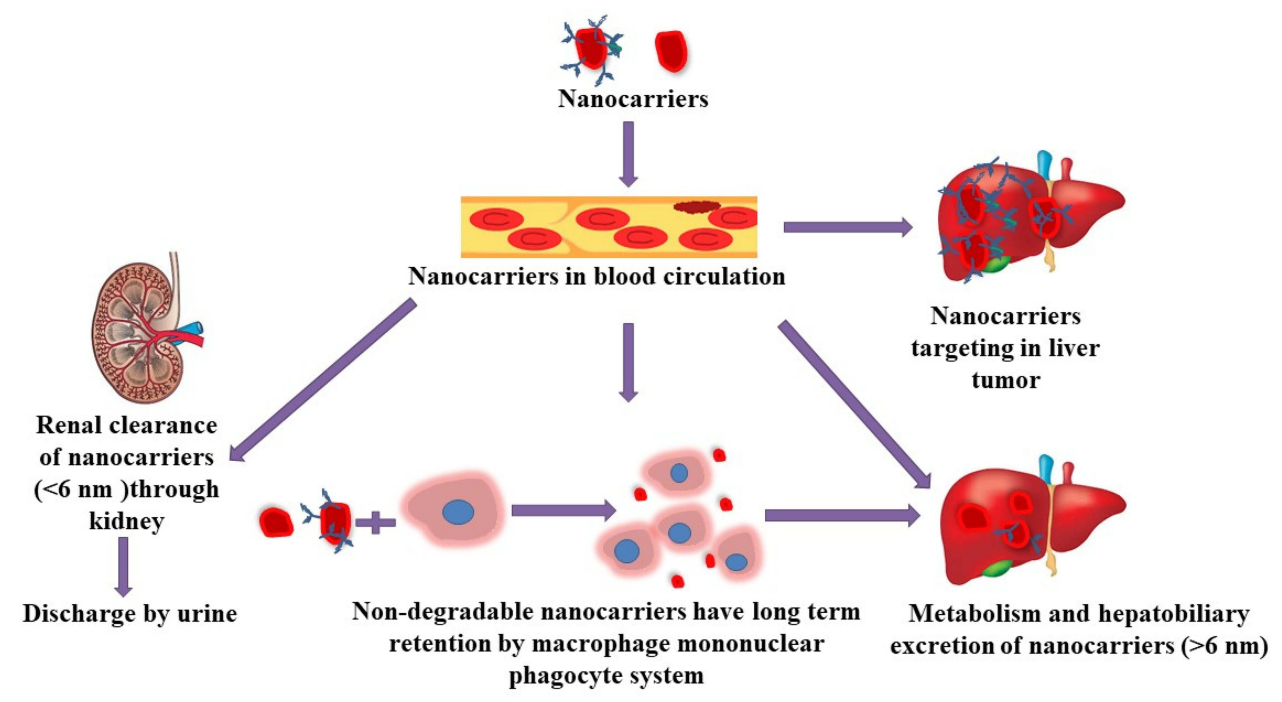

Figure 5 Schematic diagram showing possible nanocarriers clearance.

termed as "enhanced permeability and retention" (EPR). Accumulation of drugs loaded in NCs by passive targeting usually occurs via the EPR effect. ${ }^{84}$ Nowadays scientists are focusing on development and design of NCs system that can deliver drug molecules directly to liver cancer cells either via passive targeting pathway based on the EPR effect or via active targeting mediated by tumorspecific targeting ligands. Both passive and active targeting can potentially accumulate chemotherapeutic drugs into the targeted liver cells and decrease the accumulation of drug into healthy tissues. ${ }^{85} \mathrm{NCs}$ rapidly pass from the systemic circulation to the vessels after injected and cross the vascular barrier to enter the tumor region. Once NCs have crossed the vascular barrier, they must interact with the tumor microenvironment.

\section{Strategies for Passive Targeting to Liver}

Passive targeting refers to the nanocarriers uptake or transport to the cancer region through leaky vasculature that makes a pathway for the nanosized carrier to enter tumorous cells by passive diffusion. According to Bae \& Park (2011), the tumor tissue has abnormal leaky vasculature which helps nanocarrier to enter it. This phenomenon is called enhanced permeation and retention (EPR) effect. ${ }^{86}$ The EPR effect was first written by Matsumura and Maeda in 1986 which helps in the accumulation of nanocarrier passively which can be taken up in the liver for therapeutics drug delivery. ${ }^{87}$ Figure 6 shows the passive targeting of nanocarriers to the liver cells. The passive targeting approach usually depends on the physico-chemical properties of the nanocarrier such as size, the surface of the drug as

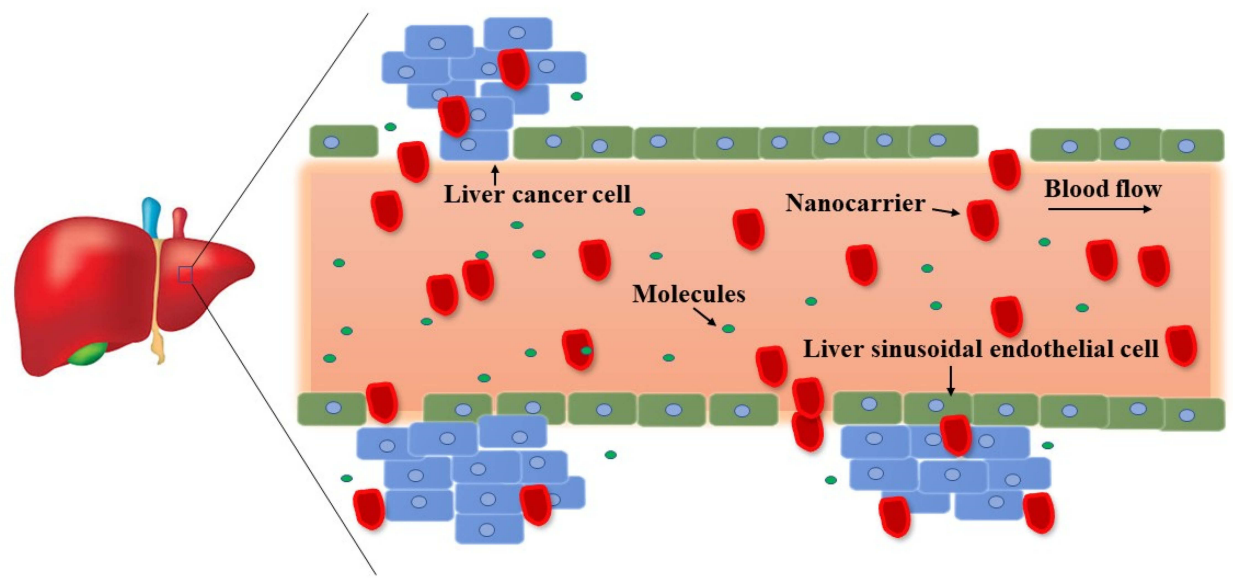

Figure 6 Passive targeting of nanocarriers to the liver cells. 
well as carriers which increase the nanocarriers accumulation in the liver tissues. ${ }^{88}$ The study of Prabhu et al, (2015) had reported that passive targeting also depends on some significant features of cancer cells such as temperature, abnormal vasculature, $\mathrm{pH}$, permeability and surface charge of tumor cells. ${ }^{89}$ Furthermore, Ferreira et al, (2013) had illustrated that some physico-chemical properties of nanocarriers such as size, molecular weight, surface charge, hydrophobicity, a hydrophilic feature which are significant for passive targeting of drug delivery. ${ }^{90}$ The liver endothelial wall has sinusoids capillaries which present $100-200$ $\mathrm{nm}$ fenestrations to facilitate the passive accumulation of nanocarrier to targeted cancerous tissues. Nanocarriers less than $200 \mathrm{~nm}$ facilitate passive targeting into the liver because these particles can easily be removed through larger sinusoidal fenestrations. ${ }^{91}$ Bae \& Park (2011) have reported that the advantage of passive targeting drug delivery systems is that drugs in nanocarriers stay for a longer period in the blood circulation. Prolonged duration in the circulation gives the EPR effect and therefore the significant level of drug carrier in the blood to accumulate the nanocarriers in the targeted area in the liver cells. ${ }^{86}$ When nanocarriers enter the bloodstream, they have a non-specific interaction with serum proteins to form a "protein corona". After interaction with the biological fluid, it may cause the aggregation of nanocarriers and change the functionality of the carriers influenced by the physico-chemical properties of the nanocarriers. ${ }^{73}$ Protein corona leads to low accumulation of the drug in the cancer cell due to the EPR effect. In addition, due to the large size of NCs, the carriers cannot slip between the endothelial cells lining and normal blood vessels in the EPR effect. It was found that the size, diameter and surface properties of protein corona influence the outcome of passive targeting. ${ }^{92}$ The liver KCs uptake these NCs while they arrive on the wall of the sinusoids and thus accumulate in the liver. ${ }^{93}$ The drug is then released adequately into the liver cancer cells. Therefore, the surface of the NCs may need to be modified by polymers, stabilizer or proteins for enhancement of their affinity to cells and reduce protein corona. $^{94}$

\section{Strategies for Active Targeting to Liver}

Active targeting occurs when nanocarriers conjugate with ligands or targeting moieties. Specific receptors or antigens molecules are attached on the surface of nanocarriers, which target the active site of the tumor followed by the accumulation of drug nanocarriers uptake at the site of action. Liver cells such as Kupffer cells, endothelial cells, hepatocytes, hepatocellular carcinoma cells have various specific receptors which bind to specific surface ligands on nanocarriers. ${ }^{7}$ These ligands can be recognized by their receptors presents on liver cancer cells, which allowed the binding of the nanodelivery system to the cell surface, triggering drug released into tumor cells. For example, HCC cell has asialoglycoprotein (ASGP) receptor where ligands from nanocarrier like galactoside, galactosamine, lactose, sterylglucoside, pullulan, lactobionic acid complementarily bind to ASGP receptor. ${ }^{95}$ Bioactive moieties such as chemotherapeutic drug or specific gene will be released into the liver cancer specific site after the nanocarriers bind to the surface. Figure 7 shows the active targeting strategies of nanocarrier for liver. After administration, the modified nanocarriers with specific ligands on the surface can be recognized by their receptors presents on a specific type of liver cells. As shown in Figure 8, there are five different liver cells; hepatocyte, hepatocellular carcinoma cell, hepatic

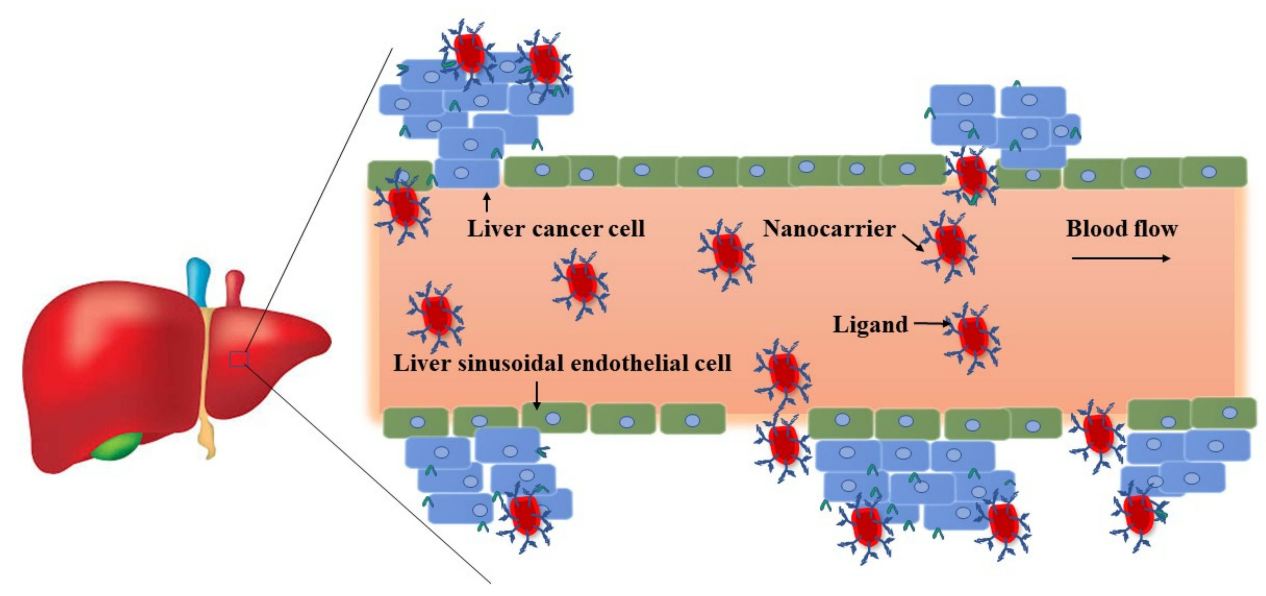

Figure 7 Active targeting of nanocarriers to the liver. 




Figure 8 Receptors present on liver cells for nanocarriers binding via active targeting to the liver cells.

stellate cell (HSC), Kupffer cell and endothelial cell. ${ }^{96}$ Each hepatic cell expressed different types of receptors that allowed the binding of the nanocarriers. Nanocarrier with active targeting moieties must be in physical contact with the receptor present on liver cancer cells. The carrier molecules must be capable of penetrating the stomach and intestine as well as recognized by the receptor present on liver cells. Glypican-3A is recently reported as a promising biomarker for hepatocellular carcinoma. ${ }^{95}$

In active targeting, scientists developed different gene silencing technologies such as antisense technologies, small activating RNAs (saRNAs) for liver tumor targeting. The development of a saRNAs upregulates the enhancer binding protein $\alpha$ (CEBPA). The CEBPA gene encodes C/EBP- $\alpha$ which is described as a transcription factor for liver function. The upregulation of C/EBP- $\alpha$ activity limits HCC growth. The C/EBP- $\alpha$ pathway activation is a therapeutic target for saRNA, to inhibit liver tumor growth. The CEBPA gene identified a saRNA sequence that upregulates CEBPA mRNA in human hepatocellular carcinoma cells. This saRNA activates the CEBPA mRNA and inhibits the growth of liver cancer cell lines in vitro. ${ }^{97} \mathrm{Kim}$ et al (2019) evaluated $\mathrm{N}$-acetylgalactosamine (GalNAc) conjugation to antisense oligonucleotides (ASO) as a novel therapeutic approach that enhanced the antitumor activity in the HCC tumor model. ADP-ribosylation 4C (ARL4C) is a small
GTP-binding protein that is highly expressed in primary HCC tumors. ${ }^{98}$ Harada et al (2019) have modified antisense oligonucleotide (ASO) which effectively reduced ARL4C expression in HCC. They suggested that ARL4C ASO can be used as a novel targeted nucleic acid for the treatment of primary liver cancer. ${ }^{99}$

\section{The Design of Drug Delivery System for Liver Cancer, Its Clinical Success and Limitations}

Nanocarrier-based drug delivery systems (DDS) will be the future generation of DDS of liver diseases such as hepatitis, liver fibrosis, hepatocellular carcinoma due to few side effects, low drug distribution in normal cells and high drug distribution in target tumor cells. Nanocarriers must be nontoxic, biodegradable, biocompatible and physicochemically stable. The uptake and interaction of nanocarriers must be suitable for liver cells. ${ }^{7}$ Figure 9 shows a schematic diagram of targeted drug delivery to the hepatocellular carcinoma orthotopic model. However, the clinical phases are still slow, and more studies need to be done for the sake of the benefit of the human.

The nanomedicines have marketed at a slow phase as the clinical phase needs to be recapitulated. The poor survival rate of nanomedicines demands its improvement 


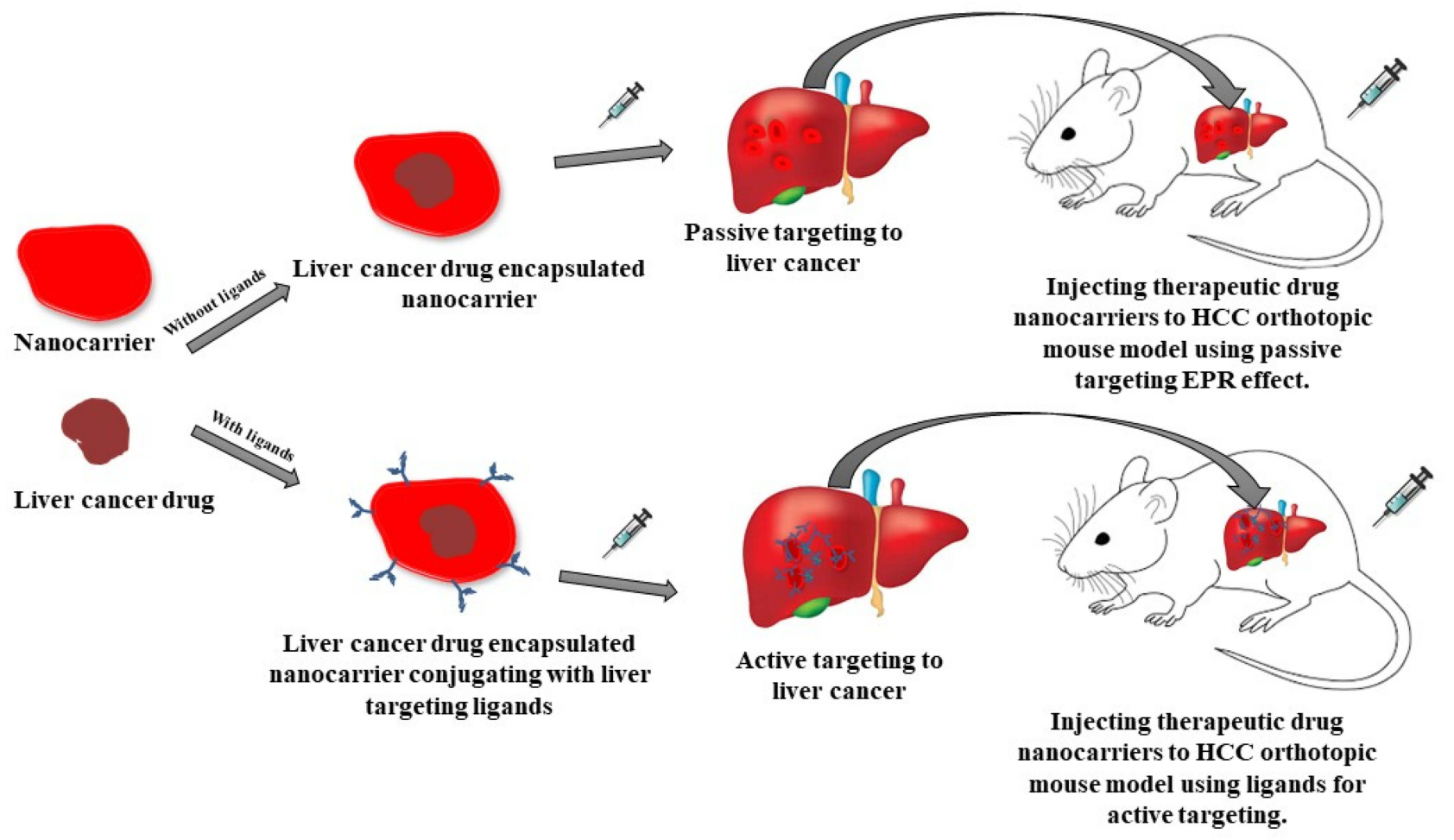

Figure 9 Nanocarrier encapsulated liver cancer drug for drug delivery to the hepatocellular carcinoma $(\mathrm{HCC})$ orthotopic model.

in therapeutic and diagnostic fields for better survival of patients. $^{100}$

In 2009, Zhou et al, (2009) evaluated the Phase II clinical trial to test the activity and toxicity of mitoxantrone (di-hydroxy-anthracenedione, DHAD)-loaded polybutyl-cyanacrylate nanoparticles (DHAD-PBCA-NPs) and DHAD. They injected both nanoparticles and DHAD in Chinese patients with unresected HCC. The response rate of DHAD-PBCA-NPs was $10.5 \%, 28.1 \%$ of patients had progression compared to $61.4 \%$ of patients with stable disease. DHAD injection showed no response, $54.9 \%$ of patients had progression and $45.1 \%$ of patients had stable disease. ${ }^{101}$ Preclinical studies showed that DHAD-PBCANPs showed better tumor-inhibiting effect than DHAD injection in HCC nude mice. ${ }^{102}$

There are many reasons for the limitations of nanocarrier systems. The designed nanocarriers cannot function effectively if they access at disease specific sites in an insufficient dose. As a result, the clinical translation of nanocarriers with the drug has been limited. ${ }^{86,103}$ The biological environment such as $\mathrm{pH}$, protein, and enzyme often creates hostile conditions for nanocarriers. ${ }^{104}$ The injected nanocarriers often face many physical and biological barriers such as protein adsorption, diffusion, aggregation, shear forces, renal clearance, phagocytic sequestration, etc. These barriers have a negative effect on reaching the target diseased tissue or cells. ${ }^{105-108}$ According to the analysis by Wilhelm et al, (2016), only $0.7 \%$ (median) of the administered nanoparticles dose was found to be delivered to a solid tumor. This means that 7 out of 1000 administered nanoparticles capable of entering a solid tumor mouse model. ${ }^{73}$ According to Park (2013), less than $95 \%$ of nanocarriers are ended up at the nontargeted sites, the rest $5 \%$ of administered nanocarriers can end up at the tumor site. In addition, most of the tumor cells express receptors but in the period of nanocarriers' arrival to the tumor cells, it may not have overexpressed receptors. ${ }^{109}$ As a result, only limited outcomes were found for nanomedicine. Although there are some challenges in nanotechnology fields for the development of nanocarrier systems, these nanocarriers for drug delivery for the purpose of liver anticancer therapy and imaging have been evolved significantly.

\section{Conclusion}

There are many limitations to conventional approaches for liver cancer therapy. Due to the non-specific interaction with cells, side effects, lack of drug targeting, the 
resistance of the liver cancer cells, problems with the permeability, solubility and stability of anticancer drugs, chemotherapy does not provide holistic treatment for liver cancer. In contrast, nanocarrier for liver cancer has shown significant prospects for solving problems in liver cancer chemotherapy. Nanocarriers are capable of high drug loading capacity, high stability, excellent tolerability, drug degradation, reduce multidrug resistance, controlled release and sustained delivery of anticancer drugs. Therefore, therapeutics and theranostics drug delivery nanocarrier systems have important advantages over conventional treatment methods. The development of a variety of nanotechnology platforms such as theranostic nanocarriers has considerable promise as the next generation of medicine that enables the early detection of disease, simultaneous monitoring and treatment, and targeted therapy with minimal toxicity to diagnose and treat liver cancer.

Nanomedicine. in particlur nanocarriers have a huge potential in future liver cancer holistic management. However, there are many challenges needed to be solved in drug delivery systems, such as excessive accumulation of the carriers in the liver, low therapeutic efficacy on the cancer cells and some barriers near the tumor areas or in vasculature area that create obstacles to penetration into liver cancer cells needed to be overcome. The ligands or targeting moieties need to translocate the nanocarriers to a specific region of tumors to achieve the site-specific delivery of nanodrugs. The current nanotherapeutic systems have developed only a limited number of clinically approved nanodrugs for liver cancer. There are many new therapeutic drugs with diverse physico-chemical properties of nanocarriers need to be invented to achieve adequate therapeutic payload and imaging sensitivity. Moreover, the controlled release of various drugs from its nanocarrier in liver cancer is another challenge in the development of nanomaterials that need further studies.

\section{Acknowledgments}

This work was supported by Grant Putra Berimpak, UPM/800-3/3/1/GPB/2019/9678800, Vot. No. 9678800 Universiti Putra Malaysia. A special thanks to Gergia Pastorin (Faculty of Pharmacy, National University of Singapore) for the cooperation with revising the manuscript.

\section{Disclosure}

The authors report no conflicts of interest in this work.

\section{References}

1. Jemal A, Bray F, Center M. Global cancer statistics. CA Cancer J Clin. 2011;61(2):69-90. doi:10.3322/caac.20107

2. Sia D, Villanueva A, Friedman SL, Llovet JM. Liver cancer cell of origin, molecular class, and effects on patient prognosis. Gastroenterology. 2017;152:745-761. doi:10.1053/ j.gastro.2016.11.048

3. Azzariti A, Iacobazzi RM, Fanizza E, et al. Sorafenib delivery nanoplatform based on superparamagnetic iron oxide nanoparticles magnetically targets hepatocellular carcinoma. Nano Res. 2017;10(7):2431-2448. doi:10.1007/s12274-017-1444-3

4. Chabner BA, Roberts TG. Chemotherapy and the war on cancer. Nat Rev Cancer. 2005;5(1):65. doi:10.1038/nrc1529

5. Kiparissides C, Kammona O. Nanoscale carriers for targeted delivery of drugs and therapeutic biomolecules. Can J Chem Eng. 2013;91(4):638-651. doi:10.1002/cjce.v91.4

6. Zhang N, Yu R, Cheng XY, et al. Visual targeted therapy of hepatic cancer using homing peptide modified calcium phosphate nanoparticles loading doxorubicin guided by $\mathrm{T} 1$ weighted MRI. Nanomedicine. 2018. doi:10.1016/j.nano.2018.06.014

7. Mishra N, Yadav NP, Rai VK, et al. Efficient hepatic delivery of drugs: novel strategies and their significance. Biomed Res Int. 2013;2013. doi:10.1155/2013/382184

8. Lata S, Sharma G, Joshi M, Kanwar P, Mishra T. Role of nanotechnology in drug delivery. Int $J$ Nanotechnol Nanosci. 2017;5:1-29.

9. Yang T, Lan Y, Cao M, et al. Glycyrrhetinic acid-conjugated polymeric prodrug micelles co-delivered with doxorubicin as combination therapy treatment for liver cancer. Colloids Surf B. 2019. doi:10.1016/j.colsurfb.2018.11.082

10. Barenholz YC. Doxil ${ }^{\circledR}$ - the first FDA-approved nano-drug: lessons learned. J Controll Release. 2012;160(2):117-134. doi:10.1016/j.jconrel.2012.03.020

11. Wang B, Qiao W, Wang Y, Yang L, Zhang Y, Shao P. Cancer therapy based on nanomaterials and nanocarrier systems. J Nanomater. 2010;2010. doi:10.1155/2010/796303

12. Masood F. Polymeric nanoparticles for targeted drug delivery system for cancer therapy. Mater Sci Eng C. 2016;60:569-578. doi:10.1016/j.msec.2015.11.067

13. Tang X, Lyu Y, Xie D, Li A, Liang Y, Zheng D. Therapeutic effect of sorafenib-loaded TPGS-b-PCL nanoparticles on liver cancer. J Biomed Nanotechnol. 2018;14(2):396-403. doi:10.1166/jbn.2018.2529

14. Lee AY, Choi Y-J, Cho C-S, et al. Combination therapy with doxorubicin-loaded galactosylated poly(ethyleneglycol)-lithocholic acid to suppress the tumor growth in an orthotopic mouse model of liver cancer. Biomaterials. 2016;116:130-144. doi:10.1016/j. biomaterials.2016.11.040

15. Ye B, Zheng R, Ruan X, et al. Chitosan-coated doxorubicin nano-particles drug delivery system inhibits cell growth of liver cancer via p53/PRC1 pathway. Biochem Biophys Res Commun. 2018;495(1):414-420. doi:10.1016/j.bbrc.2017.10.156

16. Loutfy SA, El-Din HMA, Elberry MH, Allam NG, Hasanin MTM, Abdellah AM. Synthesis, characterization and cytotoxic evaluation of chitosan nanoparticles: in vitro liver cancer model. Adv Nat Sci. 2016;7(3):035008.

17. Huang W, Wang W, Wang P, et al. Glycyrrhetinic acid-modified poly(ethylene glycol)-b-poly( $\gamma$-benzyl l-glutamate) micelles for liver targeting therapy. Acta Biomater. 2010. doi:10.1016/j. actbio.2010.04.021

18. Blanco E, Kessinger CW, Sumer BD, Gao J. Multifunctional micellar nanomedicine for cancer therapy. Exp Biol Med. 2008. doi:10.3181/0808-mr-250 
19. Hanafy NAN, Quarta A, Ferraro MM, et al. Polymeric nano-micelles as novel cargo-carriers for LY2157299 liver cancer cells delivery. Int J Mol Sci. 2018. doi:10.3390/ijms19030748

20. Immordino ML, Dosio F, Cattel L. Stealth liposomes: review of the basic science, rationale, and clinical applications, existing and potential. Int J Nanomedicine. 2006;1(3):297-315.

21. Xiang G, Khan MW, Madni A, et al. Liposomal co-delivered oleanolic acid attenuates doxorubicin-induced multi-organ toxicity in hepatocellular carcinoma. Oncotarget. 2017;8:29. doi:10.18632/oncotarget.17559

22. Yang G, Yang T, Zhang W, Lu M, Ma X, Xiang G. In vitro and in vivo antitumor effects of folate-targeted ursolic acid stealth liposome. J Agric Food Chem. 2014;62(10):2207-2215. doi:10.1021/jf405675g

23. Wang J, Wu Z, Pan G, et al. Enhanced doxorubicin delivery to hepatocellular carcinoma cells via CD147 antibody-conjugated immunoliposomes. Nanomedicine. 2018;14(6):1949-1961. doi:10.1016/j.nano.2017.09.012

24. Persico M, Barbarisi M, Armenia E, et al. Chitosan-coated liposomes loaded with butyric acid demonstrate anticancer and anti-inflammatory activity in human hepatoma HepG2 cells. Oncol Rep. 2018. doi:10.3892/or.2018.6932

25. He Q, He X, Deng B, et al. Sorafenib and indocyanine green co-loaded in photothermally sensitive liposomes for diagnosis and treatment of advanced hepatocellular carcinoma. J Mater Chem B. 2018;6(36):5823-5834. doi:10.1039/c8tb01641k

26. Noriega-Luna B, Godínez LA, Rodríguez FJ, Rodríguez A, Zaldívar-lelo De Larrea G, Sosa-Ferreyra Bustos E. Applications of dendrimers in drug delivery agents, diagnosis, therapy, and detection. $J$ Nanomater. 2014;2014:1-19. doi:10.1155/2014/507273

27. Peer D, Karp JM, Hong S, Farokhzad OC, Margalit R, Langer R. Nanocarriers as an emerging platform for cancer therapy. Nat Nanotechnol. 2007;2(12):751-760. doi:10.1038/ nnano.2007.387

28. Wojnarowicz J, Jesionowski T, Grześkowiak BF, et al. Dendrimer based theranostic nanostructures for combined chemo- and photothermal therapy of liver cancer cells in vitro. Colloids Surf B. 2018;173:698-708. doi:10.1016/j.colsurfb.2018.10.045

29. Sharma AK, Gothwal A, Kesharwani P, Alsaab H, Iyer AK, Gupta U. Dendrimer nanoarchitectures for cancer diagnosis and anticancer drug delivery. Drug Discov Today. 2017;22 (2):314-326. doi:10.1016/j.drudis.2016.09.013

30. Fu F, Wu Y, Zhu J, Wen S, Shen M, Shi X. Multifunctional lactobionic acid-modified dendrimers for targeted drug delivery to liver cancer cells: investigating the role played by PEG spacer. ACS Appl Mater Interfaces. 2014;6(18):16416-16425. doi:10.1021/am504849x

31. Jain NK, Mody N, Tekade RK, Chopdey PK, Mehra NK. Glycyrrhizin conjugated dendrimer and multi-walled carbon nanotubes for liver specific delivery of doxorubicin. J Nanosci Nanotechnol. 2014;15(2):1088-1100. doi:10.1166/jnn.2015.9039

32. Bondì $\mathrm{ML}$, Botto $\mathrm{C}$, Amore $\mathrm{E}$, et al. Lipid nanocarriers containing sorafenib inhibit colonies formation in human hepatocarcinoma cells. Int $J$ Pharm. 2015;493(1-2):75-85. doi:10.1016/j. ijpharm.2015.07.055

33. Zhao X, Chen Q, Li Y, Tang H, Liu W, Yang X. Doxorubicin and curcumin co-delivery by lipid nanoparticles for enhanced treatment of diethylnitrosamine-induced hepatocellular carcinoma in mice. Eur J Pharm Biopharm. 2015;93:27-36. doi:10.1016/j. ejpb.2015.03.003

34. Ebara M, Lee HJ, Aoyagi T, et al. Simultaneous drug and gene delivery from the biodegradable Poly(-caprolactone) nanofibers for the treatment of liver cancer. J Nanosci Nanotechnol. 2015. doi:10.1166/jnn.2015.11233
35. Ji Y, Xiao Y, Xu L, et al. Drug-bearing supramolecular MMP inhibitor nanofibers for inhibition of metastasis and growth of liver cancer. Adv Sci. 2018;5:1700867. doi:10.1002/ advs.201700867

36. Yang $\mathrm{C}$, Yang $\mathrm{C}, \mathrm{Xu} \mathrm{H}$, et al. Novel tumor-targeting, self-assembling peptide nanofiber as a carrier for effective curcumin delivery. Int J Nanomedicine. 2013;197. doi:10.2147/IJN. S55875

37. Ao M, Xiao X, Ao Y. Low density lipoprotein modified silica nanoparticles loaded with docetaxel and thalidomide for effective chemotherapy of liver cancer. Br J Med Biol Res. 2018;51. doi:10.1590/1414-431x20176650

38. Zhang X, Deng F, Tian J, et al. Improving the drug delivery characteristics of graphene oxide based polymer nanocomposites through the "one-pot" synthetic approach of single-electrontransfer living radical polymerization. Appl Surf Sci. 2016;378:22-29. doi:10.1016/j.apsusc.2016.03.207

39. Shim G, Kim MG, Park JY, Oh YK. Graphene-based nanosheets for delivery of chemotherapeutics and biological drugs. Adv Drug Deliv Rev. 2016;105:205-227. doi:10.1016/j. addr.2016.04.004

40. Yang H, Li H, Zhu L, et al. Lactobionic acid and carboxymethyl chitosan functionalized graphene oxide nanocomposites as targeted anticancer drug delivery systems Carbohydr Polym. 2016;151:812-820. doi:10.1016/j. carbpol.2016.06.024

41. Yuan Y, Zhang Y, Liu B, et al. The effects of multifunctional MiR-122-loaded graphene-gold composites on drug-resistant liver cancer. J Nanobiotechnology. 2015;13(1). doi:10.1186/s12951015-0070-z

42. Danhier F, Ansorena E, Silva JM, Coco R, Le Breton A, Préat V. PLGA-based nanoparticles: an overview of biomedical applications. $J$ Controll Release. 2012;161(2):505-522. doi:10.1016/j.jconrel.2012.01.043

43. Gao DY, Lin TT, Sung YC, et al. CXCR4-targeted lipid-coated PLGA nanoparticles deliver sorafenib and overcome acquired drug resistance in liver cancer. Biomaterials. 2015;67:194-203. doi:10.1016/j.biomaterials.2015.07.035

44. Dangi R, Hurkat P, Jain A, et al. Targeting liver cancer via ASGP receptor using 5-FU-loaded surface-modified PLGA nanoparticles. $J \quad$ Microencapsul. 2014;31(5):479-487. doi:10.3109/02652048.2013.879929

45. Elhissi A, Ahmed W, Hassan IU, Dhanak V, D'Emanuele A. Carbon nanotubes in cancer therapy and drug delivery. $J$ Drug Deliv. 2012;2012:1-10. doi:10.1155/2012/837327

46. He H, Xiao D, Pham-Huy LA, Dramou P, Pham-Huy C. Carbon nanotubes used as nanocarriers in drug and biomolecule delivery. Drug Delivery Approaches Nanosyst. 2017;163-212. doi:10.1201/9781315225371

47. Liu Z, Chen K, Davis C, et al. Drug delivery with carbon nanotubes for in vivo cancer treatment. Cancer Res. 2008;68 (16):6652-6660. doi:10.1158/0008-5472.CAN-08-1468

48. Qi X, Rui Y, Fan Y, Chen H, Ma N, Wu Z. Galactosylated chitosan-grafted multiwall carbon nanotubes for $\mathrm{pH}$-dependent sustained release and hepatic tumor-targeted delivery of doxorubicin in vivo. Colloids Surf B. 2015;133:314-322. doi:10.1016/j. colsurfb.2015.06.003

49. Ji Z, Lin G, Lu Q, et al. Targeted therapy of SMMC-7721 liver cancer in vitro and in vivo with carbon nanotubes based drug delivery system. J Colloid Interface Sci. 2012;365(1):143-149. doi:10.1016/j.jcis.2011.09.013

50. Elsayed MM, Mostafa ME, Alaaeldin E, et al. Design and characterisation of novel Sorafenib-loaded carbon nanotubes with distinct tumour-suppressive activity in hepatocellular carcinoma. Int J Nanomedicine. 2019;14:8445. doi:10.2147/IJN.S223920 
51. Bardhan R, Lal S, Joshi A, Halas NJ. Theranostic nanoshells: from probe design to imaging and treatment of cancer. Acc Chem Res. 2011;44(10):936-946. doi:10.1021/ar200023x

52. Wang Y-XJ, Leung KC-F, Zhu X-M, Wang W, Liang Q, Cheng CHK. In vivo chemoembolization and magnetic resonance imaging of liver tumors by using iron oxide nanoshell/doxorubicin/poly(vinyl alcohol) hybrid composites. Angew Chem Int Ed. 2014;53(19):4812-4815. doi:10.1002/anie.201402144

53. Liu SY, Liang ZS, Gao F, Luo SF, Lu GQ. In vitro photothermal study of gold nanoshells functionalized with small targeting peptides to liver cancer cells. J Mater Sci. 2010;21(2):665-674. doi:10.1007/s10856-009-3895-x

54. Zhang Y, Liu S, Wang X, et al. Prevention of local liver cancer recurrence after surgery using multilayered cisplatin-loaded polylactide electrospun nanofibers. Chin J Polym Sci. 2014. doi:10.1007/s10118-014-1491-0

55. Ye Y. Integrin Targeting for Tumor Optical Imaging. Theranostics. 2011;1:102. doi:10.7150/thno/v01p0102

56. Zhang D, Wu M, Zeng Y, et al. Lipid micelles packaged with semiconducting polymer dots as simultaneous MRI/photoacoustic imaging and photodynamic/photothermal dual-modal therapeutic agents for liver cancer. J Mater Chem B. 2016. doi:10.1039/ c5tb01827g

57. Liu Y, Yu D, Zhang N, Lu Z, Liu C, Chen Z. Gadolinium-loaded polymeric nanoparticles modified with Anti-VEGF as multifunctional MRI contrast agents for the diagnosis of liver cancer. Biomaterials. 2011;32(22):5167-5176. doi:10.1016/j. biomaterials.2011.03.077

58. Luo K, Liu G, He B, et al. Multifunctional gadolinium-based dendritic macromolecules as liver targeting imaging probes. Biomaterials. 2011;32(10):2575-2585. doi:10.1016/j. biomaterials.2010.12.049

59. Park S, Kim JW, Jeong YY, et al. Drug-loaded superparamagnetic iron oxide nanoparticles for combined cancer imaging and therapy in vivo. Angew Chem Int Ed. 2008;47(29):5362-5365. doi:10.1002/anie. 200800857

60. Wang YXJ. Current status of superparamagnetic iron oxide contrast agents for liver magnetic resonance imaging. World $J$ Gastroenterol. 2015;21(47):13400-13402. doi:10.3748/wjg. v21.i47.13400

61. Arias JL, Reddy LH, Othman M, et al. Squalene based nanocomposites: a new platform for the design of multifunctional pharmaceutical theragnostics. ACS Nano. 2011;5(2):1513-1521. doi:10.1021/nn1034197

62. Wáng YXJ, Idée JM. A comprehensive literatures update of clinical researches of superparamagnetic resonance iron oxide nanoparticles for magnetic resonance imaging. Quant Imaging Med Surg. 2017;7(1):88. doi:10.21037/qims.2017.02.09

63. Bao Y, Sherwood JA, Sun Z. Magnetic iron oxide nanoparticles as $\mathrm{T} 1$ contrast agents for magnetic resonance imaging. $J$ Mater Chem C. 2018;6(6):1280-1290. doi:10.1039/C7TC05854C

64. Azria D, Blanquer S, Verdier JM, Belamie E. Nanoparticles as contrast agents for brain nuclear magnetic resonance imaging in Alzheimer's disease diagnosis. J Mater Chem B. 2017;5 (35):7216-7237. doi:10.1039/C7TB01599B

65. Wang YXJ. Superparamagnetic iron oxide-based MRI contrast agents: current status of clinical application. Quant Imaging Med Surg. 2011;1(1):35.

66. Olerile LD, Liu Y, Zhang B, et al. Near-infrared mediated quantum dots and paclitaxel co-loaded nanostructured lipid carriers for cancer theragnostic. Colloids Surf B. 2017. doi:10.1016/j. colsurfb.2016.11.032

67. Das RK, Mohapatra S. Highly luminescent, heteroatom-doped carbon quantum dots for ultrasensitive sensing of glucosamine and targeted imaging of liver cancer cells. J Mater Chem B. 2017. doi:10.1039/c6tb03141b
68. Shao D, Li J, Pan Y, et al. Noninvasive theranostic imaging of HSV-TK/GCV suicide gene therapy in liver cancer by folate-targeted quantum dot-based liposomes. Biomater Sci. 2015;3(6):833-841. doi:10.1039/C5BM00077G

69. Al-Jamal WT, Al-Jamal KT, Cakebread A, Halket JM, Kostarelos K. Blood circulation and tissue biodistribution of lipid-quantum dot (L-QD) hybrid vesicles intravenously administered in mice. Bioconjug Chem. 2009;20:1696-1702. doi:10.1021/bc900047n

70. Bhatia SN, Underhill GH, Zaret KS, Fox IJ. Cell and tissue engineering for liver disease. Sci Transl Med. 2014;6(245). doi:10.1126/scitranslmed.3005975

71. Park JK, Utsumi T, Seo YE, et al. Cellular distribution of injected PLGA-nanoparticles in the liver. Nanomedicine. 2016;12 (5):1365-1374. doi:10.1016/j.nano.2016.01.013

72. Kang KW, Song MG. Organic nanomaterials: liposomes, albumin, dendrimer, polymeric nanoparticles. In: Lee $D$ (editor). Radionanomedicine. Biological and Medical Physics, Biomedical Engineering. Cham: Springer; 2018:105-123. doi:10.1007/978-3-319-67720-0_5

73. Wilhelm S, Tavares AJ, Dai Q, et al. Analysis of nanoparticle delivery to tumours. Nat Rev Mater. 2016;1(5):16014. doi:10.1038/natrevmats.2016.14

74. Syed A, Chan WC, editors. How nanoparticles interact with cancer cells. In: Nanotechnology-Based Precision Tools for the Detection and Treatment of Cancer. Cham: Springer; 2015:227-244.

75. Kuhn DA, Vanhecke D, Michen B, et al. Different endocytotic uptake mechanisms for nanoparticles in epithelial cells and macrophages. Beilstein J Nanotechnol. 2014;5:1625-1636. doi:10.3762/bjnano.5.174

76. Huotari J, Helenius A. Endosome maturation. EMBO J. 2011;30 (17):3481-3500. doi:10.1038/emboj.2011.286

77. Treuel L, Jiang X, Nienhaus GU. New views on cellular uptake and trafficking of manufactured nanoparticles. $J R$ Soc Interface. 2013;10:20120939. doi:10.1098/rsif.2012.0939

78. Chatterjee N, Eom HJ, Choi J. A systems toxicology approach to the surface functionality control of graphene-cell interactions. Biomaterials. 2014;35(4):1109-1127. doi:10.1016/j. biomaterials.2013.09.108

79. Champion JA, Walker A, Mitragotri S. Role of particle size in phagocytosis of polymeric microspheres. Pharm Res. 2008;25 (8):1815-1821. doi:10.1007/s11095-008-9562-y

80. Vauthier C, Dubernet C, Chauvierre C, Brigger I, Couvreur P. Drug delivery to resistant tumors: the potential of poly (alkyl cyanoacrylate) nanoparticles. J Controll Release. 2003;93 (2):151-160. doi:10.1016/j.jconrel.2003.08.005

81. Li H, Cui Y, Liu J, et al. Reduction breakable cholesteryl pullulan nanoparticles for targeted hepatocellular carcinoma chemotherapy. $J$ Mate Chem B. 2014;2(22):3500-3510. doi:10.1039/C4TB00321G

82. Fujimoto T, Kogo H, Nomura R, Une T. Isoforms of caveolin-1 and caveolar structure. J Cell Sci. 2000;113(19):3509-3517.

83. Zhang YN, Poon W, Tavares AJ, McGilvray ID, Chan WC. Nanoparticle-liver interactions: cellular uptake and hepatobiliary elimination. J Controll Release. 2016;240:332-348. doi:10.1016/ j.jconrel.2016.01.020

84. Maeda H, Nakamura H, Fang J. The EPR effect for macromolecular drug delivery to solid tumors: improvement of tumor uptake, lowering of systemic toxicity, and distinct tumor imaging in vivo. Adv Drug Deliv Rev. 2013;65(1):71-79. doi:10.1016/j. addr.2012.10.002

85. Mohamed NK, Hamad MA, Hafez MZE, Wooley KL, Elsabahy M. Nanomedicine in management of hepatocellular carcinoma: challenges and opportunities. Int J Cancer. 2017;140 (7):1475-1484. doi:10.1002/ijc.30517 
86. Bae YH, Park K. Targeted drug delivery to tumors: myths, reality and possibility. $J$ Controll Release. 2011;153(3):198-205. doi:10.1016/j.jconrel.2011.06.001

87. Matsumura Y, Maeda H. A new concept for macromolecular therapeutics in cancer chemotherapy: mechanism of tumoritropic accumulation of proteins and the antitumor agent smancs. Cancer Res. 1986;46:6387-6392.

88. Xiao K, Li Y, Luo J, et al. The effect of surface charge on in vivo biodistribution of PEG-oligocholic acid based micellar nanoparticles. Biomaterials. 2011;32(13):3435-3446. doi:10.1016/j.biomaterials.2011.01.021

89. Prabhu RH, Patravale VB, Joshi MD. Polymeric nanoparticles for targeted treatment in oncology: current insights. Int J Nanomedicine. 2015;10:1001-1018. doi:10.2147/IJN S56932

90. Ferreira DDS, Lopes SCDA, Franco MS, Oliveira MC. PHsensitive liposomes for drug delivery in cancer treatment. Ther Deliv. 2013;4(9):1099-1123. doi:10.4155/tde.13.80

91. Xia Q, Li L, Zhao L. Silica nanoparticle-based dual-responsive nanoprodrug system for liver cancer therapy. Exp Ther Med. 2017;14:2071-2077. doi:10.3892/etm.2017.4768

92. Narayan R. Encyclopedia of Biomedical Engineering. Elsevier; 2018 .

93. Walkey CD, Chan WCW. Understanding and controlling the interaction of nanomaterials with proteins in a physiological environment. Chem Soc Rev. 2012;41(7):2780-2799. doi:10.1039/c1cs15233e

94. Nkansah P, Antipas A, Lu Y, et al. Development and evaluation of novel solid nanodispersion system for oral delivery of poorly water-soluble drugs. J Controll Release. 2013;169(1-2):150-161. doi:10.1016/j.jconrel.2013.03.032

95. Zhou F, Shang W, Yu X, Tian J. Glypican-3: a promising biomarker for hepatocellular carcinoma diagnosis and treatment. Med Res Rev. 2018;38(2):741-767. doi:10.1002/ med. 21455

96. Roberts MS, Liang X, Bridle KR, et al. Diagnostic imaging and therapeutic application of nanoparticles targeting the liver J Mater Chem B. 2014;3(6):939-958. doi:10.1039/c4tb01611d

97. Voutila J, Reebye V, Roberts TC, et al. Development and mechanism of small activating RNA targeting CEBPA, a novel therapeutic in clinical trials for liver cancer. Mol Ther. 2017;25 (12):2705-2714. doi:10.1016/j.ymthe.2017.07.018

98. Kim Y, Jo M, Schmidt J, et al. Enhanced potency of GalNAc-conjugated antisense oligonucleotides in hepatocellular cancer models. Mol Ther. 2019;27(9):1547-1557. doi:10.1016/j. ymthe.2019.06.009

99. Harada T, Matsumoto S, Hirota S, et al. Chemically modified antisense oligonucleotide against ARL4C inhibits primary and metastatic liver tumor growth. Mol Cancer Ther. 2019;18 (3):602-612. doi:10.1158/1535-7163.MCT-18-0824

100. Hare JI, Lammers T, Ashford MB, Puri S, Storm G, Barry ST. Challenges and strategies in anti-cancer nanomedicine development: an industry perspective. Adv Drug Deliv Rev. 2017;108:25-38. doi:10.1016/j.addr.2016.04.025

101. Zhou Q, Sun X, Zeng L, Liu J, Zhang Z. A randomized multicenter phase II clinical trial of mitoxantrone-loaded nanoparticles in the treatment of 108 patients with unresected hepatocellular carcinoma. Nanomedicine. 2009;5(4):419-423. doi:10.1016/j. nano.2009.01.009

102. Zhang ZR, He Q. Study on liver targeting and hepatocytes permeable valaciclovir polybutylcyanoacrylate nanoparticles. World J Gastroenterol. 1999;5(4):330. doi:10.3748/wjg.v5.i4.330

103. Wang AZ, Langer R, Farokhzad OC. Nanoparticle delivery of cancer drugs. Annu Rev Med. 2012;63:185-198. doi:10.1146/ annurev-med-040210-162544
104. Feliu N, Docter D, Heine M, et al. In vivo degeneration and the fate of inorganic nanoparticles. Chem Soc Rev. 2016;45 (9):2440-2457. doi:10.1039/C5CS00699F

105. Lazarovits J, Chen YY, Sykes EA, Chan WC. Nanoparticle-blood interactions: the implications on solid tumour targeting. Chem Commun. 2015;51(14):2756-2767. doi:10.1039/C4CC07644C

106. Nichols JW, Bae YH. Odyssey of a cancer nanoparticle: from injection site to site of action. Nano Today. 2012;7(6):606-618. doi:10.1016/j.nantod.2012.10.010

107. Jain RK, Stylianopoulos T. Delivering nanomedicine to solid tumors. Nat Rev Clin Oncol. 2010;7(11):653. doi:10.1038/ nrclinonc.2010.139

108. Florence AT. "Targeting" nanoparticles: the constraints of physical laws and physical barriers. J Controll Release. 2012;164 (2):115-124. doi:10.1016/j.jconrel.2012.03.022

109. Park K. Facing the truth about nanotechnology in drug delivery. ACS Nano. 2013;7(9):7442-7447. doi:10.1021/nn404501g

110. Su Y, Wang K, Li Y, et al. Sorafenib-loaded polymeric micelles as passive targeting therapeutic agents for hepatocellular carcinoma therapy. Nanomedicine. 2018. doi:10.2217/nnm-2018-0046

111. Xiao Y, Liu Y, Yang S, et al. Sorafenib and gadolinium co-loaded liposomes for drug delivery and MRI-guided HCC treatment. Colloids Surf B. 2016. doi:10.1016/j.colsurfb.2016.01.016

112. Zhang J, Hu J, Chan HF, Skibba M, Liang G, Chen M. iRGD decorated lipid-polymer hybrid nanoparticles for targeted co-delivery of doxorubicin and sorafenib to enhance anti-hepatocellular carcinoma efficacy. Nanomedicine. 2016. doi:10.1016/j.nano.2016.01.017

113. Malarvizhi GL, Retnakumari AP, Nair S, Koyakutty M. Transferrin targeted core-shell nanomedicine for combinatorial delivery of doxorubicin and sorafenib against hepatocellular carcinoma. Nanomedicine. 2014;10:1649-1659. doi:10.1016/j. nano.2014.05.011

114. Wang J, Zhou Y, Guo S, et al. Cetuximab conjugated and doxorubicin loaded silica nanoparticles for tumor-targeting and tumor microenvironment responsive binary drug delivery of liver cancer therapy. Mater Sci Eng C. 2017. doi:10.1016/j.msec.2017.03.131

115. Manatunga DC, de Silva RM, de Silva KMN, et al. Effective delivery of hydrophobic drugs to breast and liver cancer cells using a hybrid inorganic nanocarrier: a detailed investigation using cytotoxicity assays, fluorescence imaging and flow cytometry. Eur J Pharm Biopharm. 2018;128:18-26. doi:10.1016/j.ejpb.2018.04.001

116. Ahmad J, Wahab R, Siddiqui MA, Musarrat J, Al-Khedhairy AA. Zinc oxide quantum dots: a potential candidate to detain liver cancer cells. Bioprocess Biosyst Eng. 2015;38:155-163. doi:10.1007/s00449-014-1254-x

117. Shen AJ, Li DL, Cai XJ, et al. Multifunctional nanocomposite based on graphene oxide for in vitro hepatocarcinoma diagnosis and treatment. J Biomed Mater Res. 2012. doi:10.1002/jbm. a.34148

118. Jeon MJ, Gordon AC, Larson AC, Chung JW, Il KY, Kim DH. Transcatheter intra-arterial infusion of doxorubicin loaded porous magnetic nano-clusters with iodinated oil for the treatment of liver cancer. Biomaterials. 2016;88:25-33. doi:10.1016/j. biomaterials.2016.02.021

119. Wang Z, Shao D, Chang Z, et al. Janus gold nanoplatform for synergetic chemoradiotherapy and computed tomography imaging of hepatocellular carcinoma. ACS Nano. 2017;11:12732-12741. doi:10.1021/acsnano.7b07486

120. Saraswathy A, Nazeer SS, Nimi N, Arumugam S, Shenoy SJ, Jayasree RS. Synthesis and characterization of dextran stabilized superparamagnetic iron oxide nanoparticles for in vivo MR imaging of liver fibrosis. Carbohydr Polym. 2014;101:760-768. doi:10.1016/j.carbpol.2013.10.015 
121. Im GH, Kim SM, Lee DG, Lee WJ, Lee JH, Lee IS. Fe3O4/MnO hybrid nanocrystals as a dual contrast agent for both T1- and T2-weighted liver MRI. Biomaterials. 2013;34:2069-2076. doi:10.1016/j.biomaterials.2012.11.054

122. Zhou Z, Wang L, Chi X, et al. Engineered iron-oxide-based nanoparticles as enhanced $\mathrm{T} 1$ contrast agents for efficient tumor imaging. ACS Nano. 2013;7:3287-3296. doi:10.1021/nn305991e

123. Liu S, Zhou G, Liu D, et al. Inhibition of orthotopic secondary hepatic carcinoma in mice by doxorubicin-loaded electrospun polylactide nanofibers. J Mater Chem B. 2013. doi:10.1039/c2tb00121g

124. Guo H, Lai Q, Wang W, et al. Functional alginate nanoparticles for efficient intracellular release of doxorubicin and hepatoma carcinoma cell targeting therapy. Int J Pharm. 2013;451:1-11. doi:10.1016/j.ijpharm.2013.04.025

125. Li YJ, Dong M, Kong FM, Zhou JP. Folate-decorated anticancer drug and magnetic nanoparticles encapsulated polymeric carrier for liver cancer therapeutics. Int J Pharm. 2015. doi:10.1016/j. ijpharm.2015.04.028

126. Mouli SK, Tyler P, McDevitt JL, et al. Image-guided local delivery strategies enhance therapeutic nanoparticle uptake in solid tumors. ACS Nano. 2013;7:7724-7733. doi:10.1021/nn4023119

127. Zhang L, Gong F, Zhang F, Ma J, Zhang P, Shen J. Targeted therapy for human hepatic carcinoma cells using folate-functionalized polymeric micelles loaded with superparamagnetic iron oxide and sorafenib in vitro. Int J Nanomedicine. 2013;8:1517. doi:10.2147/IJN. S43263
128. Maeng JH, Lee DH, Jung KH, et al. Multifunctional doxorubicin loaded superparamagnetic iron oxide nanoparticles for chemotherapy and magnetic resonance imaging in liver cancer. Biomaterials. 2010;31(18):4995-5006. doi:10.1016/j. biomaterials.2010.02.068

129. Jędrzak A, Grześkowiak BF, Coy E, et al. Dendrimer based theranostic nanostructures for combined chemo- and photothermal therapy of liver cancer cells in vitro. Colloids Surf $B$. 2019;173:698-708. doi:10.1016/j.colsurfb.2018.10.045

130. Zhao Z, Han Y, Lin C, et al. Multifunctional core-shell upconverting nanoparticles for imaging and photodynamic therapy of liver cancer cells. Chem Asian J. 2012;7:830-837. doi:10.1002/ asia.201100879

131. Liu Y, Li J, Liu F, et al. Theranostic polymeric micelles for the diagnosis and treatment of hepatocellular carcinoma. J Biomed Nanotechnol. 2015. doi:10.1166/jbn.2015.1945

132. Zhang N, Yu R, Xu M, et al. Visual targeted therapy of hepatic cancer using homing peptide modified calcium phosphate nanoparticles loading doxorubicin guided by $\mathrm{T} 1$ weighted MRI. Nanomedicine. 2018. doi:10.1016/j.nano.2018.06.014
International Journal of Nanomedicine

\section{Publish your work in this journal}

The International Journal of Nanomedicine is an international, peerreviewed journal focusing on the application of nanotechnology in diagnostics, therapeutics, and drug delivery systems throughout the biomedical field. This journal is indexed on PubMed Central, MedLine, CAS, SciSearch ${ }^{\mathbb{R}}$, Current Contents ${ }^{\mathbb{R}} /$ Clinical Medicine, $^{2}$

\section{Dovepress}

Journal Citation Reports/Science Edition, EMBase, Scopus and the Elsevier Bibliographic databases. The manuscript management system is completely online and includes a very quick and fair peer-review system, which is all easy to use. Visit http://www.dovepress.com/ testimonials.php to read real quotes from published authors. 